\title{
Midbrain microglia exhibit early proliferative and inflammatory responses during aging that are modulated by CX3CR1 and microglial ablation and repopulation
}

Moca $\mathrm{EN}^{1^{*}}$, Lecca $\mathrm{D}^{2 *}$, Hope $\mathrm{KT}^{1}$, Tweedie $\mathrm{D}^{2}$, Sidhu $\mathrm{S}^{1}$, Masukawa $\mathrm{L}^{1}$, Sitoy $\mathrm{H}^{1}$, Mathew $\mathrm{R}^{3}$, Saban $\mathrm{DR}^{3}$, Greig $\mathrm{NH}^{2}$, De Biase $\mathrm{LM}^{1}$

$*$ = equal contribution

1. Department of Physiology, David Geffen School of Medicine at UCLA, Los Angeles, CA 90095

2. Intramural Research Program, National Institute on Aging, Baltimore MD, 21224

3. Department of Ophthalmology, Duke University School of Medicine, Durham NC, 27710

Correspondence: Dr. Lindsay De Biase, 10833 Le Conte Ave, CHS 77-200F, David Geffen School of Medicine at UCLA, Los Angeles, 90095

ldebiase@mednet.ucla.edu

\begin{abstract}
Microglia maintain tissue health and can critically influence synaptic connectivity and function. During aging, microglia produce inflammatory factors, show reduced tissue surveillance, altered interactions with synapses, and prolonged responses to insults. In addition, risk genes for neurodegenerative disease are highly expressed by microglia. These findings argue that microglial function is likely to critically shape vulnerability or resilience of neurons during aging. We recently discovered that microglia in the ventral tegmental area (VTA) of young adult mice differ markedly from their counterparts in other brain regions. Whether this regional variation in microglia persists, diminishes, or increases during aging has not been determined. Here, we analyze microglia in several nuclei of the basal ganglia throughout the lifespan in mice and find that VTA microglia exhibit increased proliferation and production of inflammatory factors months prior to microglia in other basal ganglia nuclei. Comparable early proliferative responses were observed in the substantia nigra pars compacta where disease-vulnerable dopamine neurons reside. These proliferative and inflammatory responses of VTA microglia began as early at 13 months of age in mice and were not accompanied by substantial neuronal loss or changes in local astrocyte number. Finally, these region-specific responses of microglia to aging were enhanced by knockout of the fractalkine receptor (CX3CR1) and reduced by microglial ablation and repopulation, identifying two signaling axes by which region-specific responses of microglia to aging can be modulated. Collectively, these findings indicate that VTA and SNc microglia continue to differ from their counterparts in other basal ganglia nuclei during aging. Moreover, the early phenotypic changes in these cells result in "pockets" of inflammation near dopamine neurons beginning in middle age, which may be linked to enhanced vulnerability of these neurons to functional decline and degenerative disease.
\end{abstract}




\section{INTRODUCTION}

Microglia shape neuronal health and function throughout the lifespan. Microglia are ubiquitous CNS cells that support CNS homeostasis and respond to virtually all known neurological disorders, diseases, and acute injuries ${ }^{1-3}$. In health, the motile processes of microglia constantly survey the environment, removing cellular debris and pathogens through phagocytosis and lysosomal degradation ${ }^{4-7}$. Microglial processes also interact with neurons and the extracellular matrix, promoting synaptogenesis, synapse remodeling, and synapse elimination, thus contributing to proper circuit maturation and ongoing plasticity ${ }^{8-11}$. These versatile cells can secrete numerous soluble signaling factors, including trophic factors, which shape neuronal survival and synaptic plasticity, as well as pro- and anti-inflammatory factors, which can influence synapse receptor composition ${ }^{8,10,12,13}$. Finally, through physical contact and metabolism of extracellular ATP, microglia shape membrane excitability of nearby neurons ${ }^{14,15}$. Many of these microglial functions were only recently identified, and many aspects of microglial capacity to support neurons in different contexts remain unexplored.

In response to CNS insults, microglia alter their cellular phenotype by proliferating, migrating, and radically altering their gene expression and secretion of signaling factors ${ }^{1,2,6}$. These microglial responses can initially be neuroprotective but frequently lead to detrimental and chronic inflammation during prolonged insults ${ }^{1,2,16}$. During aging, microglia increase production of inflammatory factors ${ }^{17,18}$, induce inflammatory phenotypes in astrocytes ${ }^{19,20}$, and exhibit prolonged injury responses ${ }^{21}$. Motility of microglial cell processes decreases ${ }^{22,23}$, suggesting that microglial-based tissue homeostasis is compromised. Finally, signals that promote microglial phagocytosis of synapses increase with aging and they engulf synapses during presymptomatic neurodegeneration ${ }^{24,25}$. These findings argue that microglia are likely key determinants of changes in neuronal viability and synaptic function that underlie compromised cognition and movement during aging. Indeed, global manipulation of microglial phenotype during aging can improve cognition ${ }^{26}$ and many recently identified risk genes for neurodegenerative disease are prominently expressed by microglia ${ }^{27,28}$.

\section{Regional variation in microglia may contribute to differences in neuronal health and} disease susceptibility. Due to their ubiquitous distribution and historically recognized role in immune surveillance, microglia were generally assumed to be equivalent throughout the CNS. We and others recently showed that, instead, microglia display regionally distinct phenotypes ${ }^{29-}$ ${ }^{34}$, suggesting that tissue homeostasis, microglial injury responses, and microglial modulation of synapses may locally vary. Focusing on basal ganglia circuits, we found that microglia in the ventral tegmental area (VTA) and substantia nigra pars compacta (SNc) differ substantially from their counterparts in striatum and cortex, showing lower density, simpler morphology, reduced lysosome content, and distinct gene expression ${ }^{29}$. Experiments by others have shown that microglial process motility ${ }^{35}$, phagocytotic activity ${ }^{31}$, and mechanisms of synapse elimination ${ }^{36}$, also vary across brain regions. The full extent of microglial heterogeneity and its impact on neuronal function is just beginning to be explored.

Here, we sought to understand whether regional specialization of microglia is maintained throughout the lifespan in mice and whether these cells exhibit regional differences in response to aging. Transcriptome studies ${ }^{30}$ and investigation of white matter microglia ${ }^{33,37}$ indicate that microglial responses to aging may vary, but the extent and nature of this variation has not been fully mapped out. Focusing on the basal ganglia, we found that VTA/SNc microglia show 
increased proliferation and production of inflammatory factors months before microglia in other basal ganglia nuclei, creating "pockets" of inflammation that are likely detrimental to health and synaptic function of dopamine neurons. Collectively, these findings reveal that local microglial responses to aging can begin as early as midlife, supporting the idea that microglial variation in response to aging may be a major contributor to neuronal vulnerability.

\section{METHODS}

\section{Transgenic mice}

C57Bl6 wildtype mice - Wildtype mice on the C57Bl6 background were purchased from Jackson labs (Stock \# 000664).

CX3CR1 ${ }^{\text {EGFP/+ }}$ mice - CX3CR1 ${ }^{\text {EGFP/EGFP }}$ breeders were originally purchased from Jackson labs (Stock \# 005582). In these mice, EGFP is knocked in to the CX3CR1 (fractalkine receptor) locus. These mice were maintained on a C57Bl/6 background and all mice used for experiments were heterozygous (CX3CR1 $1^{E G F P /+}$ ) except for analysis of homozygous $C X 3 C R 1^{E G F P / E G F P}$ mice in Fig. 8 and Fig. S6. We have shown elsewhere that EGFP expression in the basal ganglia of these mice was specific to microglial cells and $98 \pm 1 \%$ of Iba1+ microglia were EGFP+ ${ }^{29}$.

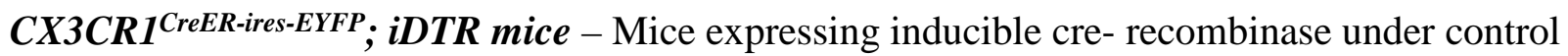
of the CX3CR1 promoter (CX3CR1 $1^{\text {Cre-ER-ires-EYFP }}$ mice) and mice expressing cre-dependent floxstop-diphtheria toxin receptor (iDTR mice) were purchased from Jackson Laboratories (Stock $\# 021160$ and \#007900). Mice used in fate mapping studies were F1 progeny of BALB/cJ and

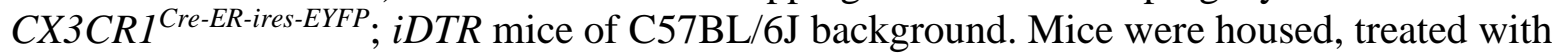
tamoxifen, and sacrificed for tissue collection in the lab of Daniel Saban at Duke University.

ALDH1L1-EGFP mice - ALDH1L1-EGFP breeders were obtained from Mutant Mouse Resource and Research Centers (MMRRC; Stock \#011015-UCD) and were originally generated by Gensat. In these BAC transgenic mice, EGFP expression is driven by the astrocyte specific aldehyde dehydrogenase 1 family member L1 promoter. All mice used for experiments were heterozygous for the transgene.

In all experiments, mice of mixed sex were used, and the number of males and females in each analysis group was balanced. Mice were housed in normal light/dark cycle and had ad libitum access to food and water. All experiments were performed in strict accordance with protocols approved by the Animal Care and Use Committees at UCLA, NIDA, and Duke.

\section{Microglial ablation}

To pharmacologically ablate microglial cells from the CNS, CX3CR1 ${ }^{E G F P /+}$ mice age $13-20$ mo were treated with the CSF1R antagonist PLX5622 (Plexxikon, Inc.) administered through the diet $(1200 \mathrm{mg} / \mathrm{kg}$ chow). Mice were maintained on PLX5622 or control AIN-76A diet for 3-4 weeks and were then returned to standard vivarium chow for 3 weeks before tissue collection for immunohistochemistry. Mice that underwent microglial ablation using this approach maintained their body weight during the PLX5622 treatment and subsequent period of microglial repopulation. These mice also appeared normal during qualitative evaluation of motor coordination and exploratory behavior. To confirm microglial cell death and quantify ablation 
efficacy, tissue was collected from some mice after they had been administered PLX5622 via diet for 7 days.

\section{Tamoxifen treatments}

Tamoxifen (Sigma-Aldrich Cat\# T5648) was dissolved in corn oil to a stock concentration of 20 $\mathrm{mg} / \mathrm{ml}$. CX3CR1 ${ }^{\text {CreER-ires-EYFP }}$; iDTR mice were given two intraperitoneal injections of tamoxifen $(75 \mathrm{mg} / \mathrm{kg}$ ) with one day in between injections at 2 mo of age. Mice were then euthanized at 2 weeks after the second injection or allowed to age to 20-24 mo.

\section{Tissue collection and immunohistochemistry}

Tissue was collected from wildtype, CX3CR1 $1^{\text {EGFP/+ }}, C X 3 C R 1^{\text {EGFP/EGFP }}$, ALDH1L1-EGFP, or $C X 3 C R 1^{\text {CreER-ires-EYFP }}$;iDTR mice between of 2-24 mo of age. Mice were deeply anesthetized with an injection of Euthasol (sodium pentobarbital $150 \mathrm{mg} / \mathrm{kg}$ and sodium phenytoin $19.2 \mathrm{mg} / \mathrm{kg}$, Virbac) and perfused transcardially with $1 \mathrm{M}$ phosphate buffered saline (PBS) followed by icecold 4\% paraformaldehyde (PFA) in 1M PBS. Microglia show circadian-based changes in morphology ${ }^{38}$; all perfusions for this study were hence performed between 9:00am-12:00pm. Brain tissue was isolated and postfixed in this solution for 4 hours at $4^{\circ} \mathrm{C}$ and then stored in $1 \mathrm{M}$ PBS with $0.1 \% \mathrm{NaAz}$.

For analysis of neuron number (Fig. 7), brains were cryoprotected in 30\% sucrose, frozen, and coronal brain sections were prepared on a cryostat at a thickness of $25 \mu \mathrm{m}$. Brain sections were collected in series, resulting in 3 sets of serially collected sections per mouse. One set of serially collected sections per mouse was stained and 3 sections at standardized anterior-posterior locations were analyzed (Fig. S5). For all other analyses, brains were not cryoprotected and coronal brain sections (60 $\mu \mathrm{m}$ thick) were prepared on a vibratome in chilled $1 \mathrm{M}$ PBS. Brain sections were grouped according to well-defined anatomical parameters and for analysis of microglial cell density (Fig. 1,5,6,8 and Fig. S6), microglial fate mapping with DTR (Fig. 2 and Fig. S1), microglial cell morphology (Fig. 3,6 and Fig. S3), and astrocyte density (Fig. 7), three brain sections containing nucleus accumbens (NAc) and three brain sections containing VTA were analyzed from each mouse. Brain sections were chosen using well-defined anatomical parameters and were matched for anterior-posterior location.

For immunohistochemistry, free-floating brain sections were permeabilized and blocked in $0.3 \%$ TritonX-100 and 5\% Normal Donkey Serum (NDS) in 1 M PBS for 2 hours with rotation at room temperature (RT). Sections were incubated with primary antibodies prepared in $0.05 \%$ TritonX-100 and 5\% NDS in 1M PBS at 4C overnight. Sections were incubated with secondary antibodies prepared in 5\% NDS in 1M PBS for 2 hours at RT. Control sections incubated with secondary antibody alone did not result in labeling of cells. Primary antibodies used included the following: chicken anti-GFP (1:1000; Aves, Tigard, OR Cat\#GFP-1020), goat anti-GFP (1:1000; Frontier Institute, Hokkaido, Japan, Cat\#GFP-Go-Af1480), rabbit anti-Iba1 (1:500; Wako, Richmond, VA, Cat\#019-19741), goat anti-DTR (R\&D Systems AF259), rat anti-CD68 (1:200; clone FA-11, AbD Serotec, Raleigh, NC, Cat\#MCA1957), mouse anti-tyrosine hydroxylase (1: 5000; Sigma, St. Louis, MO, Cat\#T1299), chicken anti-tyrosine hydroxylase (1:500; Aves, Tigard, OR, Cat\#TYH), mouse anti-NeuN (clone A60, 1:500; Millipore, Billerica, MA Cat\#MAB377), rat anti-BrdU (1:500; Accurate Chemical and Scientific, Westbury, NY). Primary antibodies have been validated for use in immunohistochemistry in mouse tissue in 
published literature and on the manufacturer's websites. Secondary antibodies used included the following: Alexa Fluor 488-, 594-, or 647- conjugated secondary antibodies to rabbit, mouse, goat, chicken, rat or guinea pig (1:1000; all raised in donkey; Jackson ImmunoResearch). A 1:4000 dilution of 4',6-diamidino-2-phenylindole (DAPI) in 1M PBS was used to stain nuclei.

\section{Image acquisition and analysis}

Fixed tissue was imaged using an Olympus FV1000 confocal microscope, a Zeiss LSM880 confocal microscope, or a Zeiss Apotome microscope. Within the NAc, analyzed images were acquired at the boundary between core and shell (identified anatomically), and include both subregions. In the VTA, analyzed images were medial to the medial lemniscus and included the parabrachial pigmented area, as well as portions of the parafasciculus retroflexus area and paranigral nucleus. For quantification of microglial or astrocyte density, stacks of confocal images (z-stacks) with a z-interval of $1.5 \mu \mathrm{m}$ were taken through a 20x objective and imported into ImageJ software for analysis. Within Image J software, maximum intensity projections of confocal z-stacks were created and cells were counted manually. For quantification of microglial tissue coverage, z-stacks were taken with a 63x objective and a z-interval of $1.5 \mu \mathrm{m}$. Within ImageJ software, the mean pixel intensity of the dimmest cell processes was measured at 10-15 locations diagonally across each image. The average of these values was taken as a threshold for determining the \% of pixels above (representing microglial cell somas and processes) and below (representing background) this threshold. For quantification of neuronal cell loss, tiled z-stacks of confocal images were taken with a 20x objective and a z-interval of $1.5 \mu \mathrm{m}$ such that the entire VTA and SNc were visualized. Stitched, maximum intensity projections were imported into ImageJ and cells were counted manually. For all image analyses 3 images from separate brain sections were analyzed per mouse to obtain an average value for that mouse. For quantification of neuronal cell loss, the total number of cells across 3 stereologically matched sections was also calculated. 3-6 mice were analyzed per brain region, per age. Sample sizes were selected to be in the upper range of published immunohistochemistry experiments. Experimenters were not blind to source brain region during image analysis.

\section{Microdissection}

CX3CR1 ${ }^{\text {EGFP/+ }}$ mice were anesthetized with Euthasol (sodium pentobarbital $150 \mathrm{mg} / \mathrm{kg}$ and sodium phenytoin $19.2 \mathrm{mg} / \mathrm{kg}$, Virbac) and perfused transcardially with $10 \mathrm{~mL}$ of oxygenated, icecold N-methyl-d-glucamine (NMDG)-based solution containing the following (in mM): 92 NMDG, 20 Hepes, $30 \mathrm{NaHCO}$, 1.2 NaH2PO4, $2.5 \mathrm{KCl}, 5$ sodium ascorbate, 3 sodium pyruvate, 2 thiourea, $10 \mathrm{MgSO}$, and 0.5 CaCl2, 10 glucose, pH 7.4 (310 mOsm). Brains were then rapidly dissected free. For RT-PCR and high sensitivity ELISA of tissue levels of inflammatory factors, horizontal midbrain sections (230 $\mu \mathrm{m}$ thick) and coronal forebrain sections (300 $\mu \mathrm{m}$ thick) were prepared using a vibratome in ice-cold NMDG-based cutting solution bubbled continuously with $95 \%$ O2/5\% CO2. After sectioning, slices remained in icecold, oxygenated NMDG solution and were transferred one at a time to a glass dissecting surface under a stereoscope maintained at $4^{\circ} \mathrm{C}$. The VTA was microdissected from horizontal midbrain sections, and NAc and overlying medial prefrontal cortex (mPFC) were microdissected from coronal forebrain sections using fine tipped forceps. Microdissected tissue was minced using a scalpel under the stereoscope before being transferred to eppendorf tubes containing $1 \mathrm{~mL}$ NMDG stored on ice. Samples were then centrifuged, NMDG removed and samples were either flash frozen (for high sensitivity ELISA protein analysis) or were resuspended in $100 \mu \mathrm{L}$ 
PicoPure RNA extraction buffer and incubated at $42^{\circ} \mathrm{C}$ for 30 min and stored in RNase-free tubes at $-80^{\circ} \mathrm{C}$ until further processing (for qPCR analysis). For qPCR of FACS- isolated microglia, following NMDG perfusion, rough coronal brain sections were prepared using a brain block and processed as described below.

\section{Tissue dissociation and flow cytometry}

The striatum and overlying cortex were microdissected from anterior brain sections and the midbrain was dissected from posterior sections. Microdissected samples were minced on a glass surface maintained at $4^{\circ} \mathrm{C}$. Samples were then transferred to Eppendorf tubes containing $1 \mathrm{~mL}$ Hibernate A and were gently dissociated using sequential trituration with fire-polished glass pipettes with openings of decreasing diameter (final pipette $\sim 0.4 \mathrm{~mm}$ diameter opening).

Resulting cell suspensions were spun down, resuspended in $300 \mu \mathrm{L} 1 \mathrm{M}$ PBS and filtered through a $40 \mu \mathrm{m}$ mesh filter. Throughout the experiment, samples were kept at $4{ }^{\circ} \mathrm{C}$ on ice. Samples were sorted using a FACS Aria I cell sorter (BD Biosciences). The population of cells containing microglia could be readily identified based on forward scattering (FSC) and side scattering (SSC) properties. A gating strategy based on FSC and SSC width and height was used to select only single cells, and reduce debris, doublets, and dead cells. Microglial cells within this population were then identified and sorted according to EGFP expression as described previously 29. Microglia were FACS sorted directly into eppendorf tubes containing $50 \mu \mathrm{L}$ PicoPure RNA extraction buffer and, following the sort, samples were incubated at $42^{\circ} \mathrm{C}$ for $30 \mathrm{~min}$, and stored in RNase-free tubes at $-80^{\circ} \mathrm{C}$ until further processing.

\section{$\underline{R N A \text { extraction and RT-PCR / ddPCR }}$}

RNA from microdissected tissues and sorted cells was isolated using the PicoPure RNA isolation kit (Arcturus Bioscience). Column filtration, washing, and elution of RNA from the columns was performed according to manufacturer's instructions in section $\mathrm{C}$ of the PicoPure RNA isolation protocol. RNA concentration and integrity was then analyzed via NanoDrop spectrophotometer. Single strand cDNAs were synthesized with Superscript III first strand cDNA synthesis kit (Invitrogen, Life Technologies), according to the manufacturer's protocol. For qPCR analysis of tissue levels of inflammatory factors, duplex RT-PCR assays were performed on technical duplicates using a FAM-labeled probe for each target gene, and a VIC-labeled probe for the endogenous control gene (Gapdh), along with TaqMan Advanced Fast PCR Master Mix (Cat\# 4444963; Life Technologies). To avoid amplification of genomic DNA contamination, primers and probes that amplify across target gene exon-exon junctions were selected when possible. RT-PCR reactions were run in a 7500 Fast TaqMan instrument using the program: $95^{\circ} \mathrm{C}$ hold for $20 \mathrm{~s}$, followed by 40 cycles of $95^{\circ} \mathrm{C}$ denaturation for $3 \mathrm{~s}$, and $60^{\circ} \mathrm{C}$ annealing and extension for $30 \mathrm{~s}$. Calculations of relative expression from Ct data were carried out according to User Bulletin \#2 for ABI Prism 7900 Sequence Detection System. For each target gene, the average Ct value for the endogenous control (Gapdh) was subtracted from the average Ct value for the target gene, to obtain $\Delta \mathrm{Ct}$. The relative expression was then plotted as $2^{-\Delta \mathrm{Ct}}$. For ddPCR analysis of tissue levels of inflammatory factors, duplex assays were performed on technical duplicates using a FAM-labeled probe for each target gene, and a VIC-labeled probe for the endogenous control gene (Gapdh). Reactions were run in a Bio-Rad QX-200 ddPCR system (Automated Droplet Generator, Thermocycler, and Droplet Reader). Thermocycler conditions were as follows: $95^{\circ} \mathrm{C}$ hold for $10 \mathrm{~min}$, followed by 40 cycles of $95^{\circ} \mathrm{C}$ denaturation for $30 \mathrm{~s}$ and $60^{\circ} \mathrm{C}$ annealing and extension for $1 \mathrm{~min}$, with a final $98^{\circ} \mathrm{C}$ for $30 \mathrm{~s}$ and using ddPCR Supermix for Probes (No 
dUTP). Calculations of absolute expression were made within Quantasoft software according to manufacturer's recommendations.

\section{Protein extraction and MesoScale analysis of cytokines}

Serum samples and brain tissue samples were evaluated in duplicate using the V-PLEX Proinflammatory Panel 1 Mouse Kit (Cat \# K15048D, MESO SCALE DIAGNOSTICS, LLC), and the following cytokines were assayed in each sample: Interferon-gamma (IFN- $\gamma$ ), Interlukin1 beta (IL-1 $\beta$ ), Interlukin-2 (IL-2), Interlukin-4 (IL-4), Interlukin-5 (IL-5), Interlukin-6 (IL-6), Interlukin-10 (IL-10), Interlukin-12p70 (IL-12p70), Chemokine Ligand 1 (CXCL1 or KC/GRO), Tumor necrosis factor-alpha (TNF $\alpha$ ). All samples were assessed following the recommended protocols suggested by the manufacturer. Tissue samples (NAc: $3.9 \pm 0.9 \mathrm{mg}$ (mean \pm sd for all tissues) (2-3 months), $4.7 \pm 2.2 \mathrm{mg}$ (17-18 months), 3.1 $\pm 0.5 \mathrm{mg}$ (22-24 months); VTA: $2.2 \pm 1.2$ mg (2-3 months), 2.7 \pm 2 . mg (17-18 months), 2.1 $\pm 0.7 \mathrm{mg}$ (22-24 months)) were homogenized in small volume tubes, (Tissue homogenizing CKMix_WP tubes) using a Precellys Evolution plus Cryolys Evolution system (Bertin Instruments). The tissues were homogenized in approximately $65 \mu \mathrm{l}$ of in a Tris-based lysis buffer (MSD Tris Lysis Buffer, Cat \# R60TX-3) with protease and phosphatase inhibitors (Halt protease \& phosphatase inhibitor single-use cocktail; Thermo Scientific, Cat \# 78442). Following homogenization, lysate was extracted from the tube, placed in a fresh eppendorf tube and centrifuged $\left(10,000 \mathrm{~g}\right.$ for 10 minutes $\left(4^{\circ} \mathrm{C}\right)$. Thereafter, the supernatant was collected into new tubes. Protein concentrations were then measured by bicinchoninic acid (BCA) assay (Micro BCA ${ }^{\mathrm{TM}}$ Protein Assay Kit, Cat \# 23235; Thermo Scientific). The resulting supernatant yielded low volumes (30-40 $\mu$ l of supernatant) with varying quantities of total protein, for NAc 0.6 to $5.7 \mu \mathrm{g} / \mu \mathrm{l}$ and for VTA 0.23 to $1.4 \mu \mathrm{g} / \mu \mathrm{l}$. Serum samples were diluted 1 in 2 with the kit dilution buffer, and then loaded into the wells of a 96 well multiplex ELISA plate. Cytokine detection signals generated for each sample were compared to a cytokine standard curve, and the serum raw data levels were then calculated by use of DISCOVERY WORKBENCH (MESO SCALE DIAGNOSTICS, LLC.) and expressed as $\mathrm{pg} / \mathrm{ml}$. Data are shown as a normalized ratio relative to 2-3 month old animals. Tissue samples were mixed with the kit dilution buffer and loaded into the wells of the 96 well multiplex ELISA plate. Due to the low volumes and total protein levels recovered from the samples, samples were loaded into the wells of the ELISAs at different total protein contents. Most NAc samples were loaded at $30 \mu \mathrm{g}$ per well, whereas the loading for NAc samples varied from 15 to $25 \mu \mathrm{g}$ per well, depending on the sample. All VTA samples were loaded at $10 \mu \mathrm{g}$ per well. Cytokine levels in tissues were calculated in the same way as the serum samples.

\section{Statistical comparisons}

All graphed values are shown as mean \pm SEM. Statistical details of experiments (statistical tests used, exact value of $n$, what $n$ represents) can be found in the results and figures legends. In general, statistical significance was assessed using one- or two-way ANOVA (Figures 1B, 2E-F, 3B-C, 4B, 4D, 5A-B, 5D, 6A-C, 6F, 7B, 7E-F, 8C-E, 8G-I, S1B-C, S2A-D, S4A-I, S6E, S6H). Posthoc comparisons were carried out using student's t-test with Bonferroni correction for multiple comparisons. Data are sufficiently normal and variance within groups is sufficiently similar for use of parametric tests. Paired t-tests were used to compare trends across two different regions within individual mice (Figures 1C, 4C, 5E, S6C-D, S6G). 


\section{RESULTS}

VTA microglia show early increases in cell density during aging. By the time mice reach two years of age, the number of microglia in cortex increases by approximately $14 \%{ }^{22}$. These increases in cortical microglial density were even greater in mice that experience loss of sensory input during aging ${ }^{39}$, suggesting that these microglial changes are shaped by altered circuit activity. Whether such increases in microglial abundance during aging are universal or vary across brain regions is virtually unexplored. In young adult mice, microglia in distinct basal ganglia nuclei exhibit prominent regional differences in cell attributes including cell density. To determine whether these regional differences in cell density are maintained during aging and how they intersect with aging-associated density increases, we analyzed microglia in two basal ganglia nuclei that show distinct densities in young adulthood, the NAc and the VTA.

In $C X 3 C R 1^{E G F P /+}$ mice, NAc microglial density remained largely consistent at 2 months (mo), $18 \mathrm{mo}$, and 22-24 mo (Fig. 1A,B). Although there was increased mouse-to-mouse variability in NAc microglial density at 22-24 mo, and some mice showed elevations in microglial density, these changes did not reach significance. In contrast, in the VTA, microglial density increased significantly at 18 mo of age, with trends toward further elevation at 22-24 mo. These increases represent a roughly $28 \%$ increase in microglial abundance at 18 mo and a $42 \%$ increase at 22-24 mo, greatly exceeding those reported in cortex. This regional difference in microglial density increase was evident at the level of individual mice (Fig. 1C). At 2 mo, microglial density was consistently higher in the NAc than in the VTA of the same mouse. This relationship began to breakdown at $18 \mathrm{mo}$, and by 22-24 mo, VTA microglial density was similar to and sometimes exceeded that of microglia in the NAc of the same mouse. These findings reveal that expansion of the microglial population during aging is highly variable across distinct regions of the CNS. Qualitatively, with increasing aging, VTA microglia also appear to exhibit breakdown of the even cell spacing, or tiling, observed in young adult mice.

Resident microglia proliferate to drive expansion of the microglial population during aging. Throughout the lifespan, microglia retain the capacity to proliferate in response to insults and challenges. To determine the mechanisms underlying age-associated expansion of basal ganglia microglia, we first treated 18 mo old mice with BrdU to mark proliferating cells and examined fixed tissue. In both the NAc and VTA, morphological profiles of dividing cells as well as EGFP+BrdU+ microglia could be observed (Fig. 2A,B). These events were infrequent in the NAc and more common in the VTA. These findings suggest that proliferation of resident microglia contributes to increases in microglial density during aging.

BrdU+ microglia showed extensive process branching and high levels of EGFP expression characteristic of resident microglia (Fig. 2A,B), rather than the simplified morphology and dimmer EGFP characteristic of perivascular or infiltrating macrophages. However, it is possible, though unlikely, that peripheral cells could infiltrate the CNS, acquire microglia like attributes ${ }^{34,40,41}$ and proliferate to drive population expansion. To determine whether observed proliferating cells are resident microglia, or infiltrating cells, we used genetic approaches to tag microglia during young adulthood and track their fate during aging. Mice expressing inducible Cre recombinase under control of the fractalkine receptor promoter

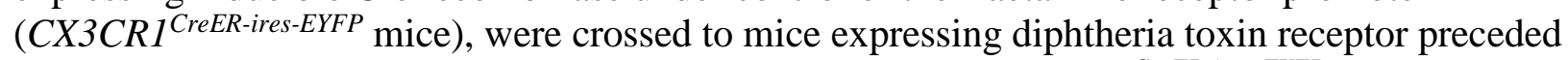
by a floxed-stopper module (iDTR mice). Double transgenic CX3CR1 ${ }^{\text {CreER-ires-EYFP }}$ iDTR mice were injected with tamoxifen at 2 mo of age and then euthanized 2 weeks later or allowed to age 
to 20-24 mo. Because mice do not normally express diphtheria toxin receptor, the expression of this receptor can act as a "tag" to label microglia" that were present in the CNS at 2 mo of age (Fig. 2C,D and Fig. S1A).

In mice euthanized 2 weeks after tamoxifen injection, quantification revealed that $95 \%$ of Iba1+ or EYFP+ microglia were DTR+, demonstrating a high recombination efficiency that will allow tracking of the majority of these cells and any resulting progeny during aging (Fig. 2E). In mice that were euthanized at 20-24 mo of age, overall microglial density had increased, consistent with previous observations in $C X 3 C R 1^{E G F P /+}$ mice (Fig. S1B). Similar to mice euthanized at 2 mo, 95\% of Iba1+ or EYFP+ microglia were DTR+ in 20-24 mo old mice (Fig. 2E). Maintenance of this percentage of DTR + microglia in aged tissue would only be possible if microglia tagged at 2 mo of age played a predominant role in proliferating and expanding the cell population. Indeed, the density of DTR+ microglia increased during aging and DTR+ cells exhibiting morphological profiles of cell division were evident in aged mice (Fig. S1C,D). Furthermore, the fold change increase in DTR+ microglia was almost identical to the fold change increase of density of the total microglial population (Fig. 2F). While these analyses do not rule out the possibility that peripheral cells can enter the CNS during aging and adopt microglial phenotypes, they indicate that the majority of microglial population expansion we observed is driven by proliferation of CNS resident microglia.

It is worth noting that we observed a significant increase in NAc microglial density in these mice by $20-24 \mathrm{mo}$ of age, which we did not observe in the $C X 3 C R 1^{E G F P /+}$ mice. The $C X 3 C R 1^{\text {CreER-ires-EYFP }}$; IDTR mice and the CX3CR $1^{E G F P /+}$ mice used in this study were aged in different vivaria and are on slightly different background strains (50\% C57Bl6 50\% BALB/cJ for CX3CR1 $1^{\text {CreER-ires-EYFP }}$; iDTR mice and $100 \%$ C57Bl6 for the CX3CR1 $1^{\text {EGFP/+ }}$ mice). These observations raise the possibility that environment and genetic background may shape the overall timing and extent of microglial proliferation during aging.

Morphological changes in basal ganglia microglia during aging. The motile processes of microglia survey the extracellular space, removing debris and interacting with synapses ${ }^{4-7}$. Aging-associated changes in microglial morphology have been reported in cortex and hippocampus and changes in cell structure also accompany early stages of neurodegenerative disease $^{1,2,42}$. To explore whether changes in cell density are accompanied by changes in cell structure, we examined high magnification images from 18 mo old $C X 3 C R 1^{E G F P /+}$ mice. In both the NAc and the VTA, the vast majority of microglia still exhibited stellate, highly branched morphologies similar to that observed in young adult mice (Fig. 3A). To assess the overall spatial relationship between microglia and the surrounding tissue, we quantified the extent to which microglial processes and somas covered the field of view. This analysis revealed that microglial tissue coverage in the NAc increased from $46 \pm 1 \%$ in 2 mo old mice to $52 \pm 2 \%$ in 18 mo old mice. Similarly, in the VTA, tissue coverage increased from $27 \pm 1 \%$ at 2 mo to $33 \pm 1 \%$ by 18 mo (Fig. 3B). In both regions, this represents a roughly 1.13-1.2 fold increase in microglial tissue coverage at 18 mo. However, the estimated tissue coverage of individual cells changed in opposite ways in each region (Fig. 3C), suggesting that increases in overall tissue coverage by the microglial population is achieved via distinct changes in cell structure in each region. In the NAc, where cell density does not change significantly at 18 mo, estimated tissue coverage of individual cells tended to increase, suggesting that individual cells experienced increases in soma size, process thickness, or overall process branching. Instead in the VTA, where microglial density increases significantly at $18 \mathrm{mo}$, tissue coverage of individual cells tended to decrease at 
18mo, likely driven by reduced process branching. This would be consistent with the qualitative observation of greater amounts of "open space” free of microglial processes in the aged VTA (Fig. 3A).

Although microglial morphology largely resembled that observed in young adult mice, some microglia in 18 mo old mice displayed morphological abnormalities not observed in young adult mice. The most prominent of these were abnormally shaped somas with large protrusions (Fig. 3D). These resemble the beginnings of cell division, but co-staining with DAPI reveal that these protrusions did not contain nuclei. Instead, they were filled with CD68+ lysosome material. These structures were observed in roughly $3.4 \pm 2 \%$ of NAc microglia and $5.6 \pm 2 \%$ of VTA microglia. Collectively, these findings indicate that subtle changes in microglial morphology are detectable by late middle age and that such changes vary across brain region.

Local increases in inflammation parallel expansion of the VTA microglial population. Microglia both contribute to and respond to inflammatory signaling and inflammation is known to increase both inside and outside the CNS during the course of aging ${ }^{43-45}$. To determine whether microglial population expansion may contribute to aging-induced CNS inflammation, we compared the time course of microglial proliferation and local changes in key inflammatory signaling factors. In microdissected NAc and VTA tissue from 2 mo, 18 mo, and 22-24 mo old $C X 3 C R 1^{E G F P /+}$ mice, we used qPCR to examine levels of key inflammatory signaling factors (Fig. 4A-C). We compared these results to those observed in microdissected mPFC which is known to show increased inflammation during aging ${ }^{46,47}$. While mPFC levels of tumor necrosis factor alpha (TNF $\alpha$ ) and interleukin 1 beta (IL-1 $\beta$ ) trended toward increases by 22-24 mo of age, these increases were significant in the NAc and VTA. In the NAc, this represented a roughly 3.7 in TNF $\alpha$ and 4.1 fold increase in IL-1 $\beta$ by 24 mo of age. In the VTA, these increases were even larger, representing a roughly 6.8 in TNF $\alpha$ and 9.5 fold in IL-1 $\beta$ by 24 mo of age. Moreover, increases in TNF $\alpha$ and IL-1 $\beta$ were already significant at 18 mo of age within the VTA. These regional differences in CNS inflammation were particularly evident when comparing levels of TNF $\alpha$ and IL-1 $\beta$ in different regions of individual mice (Fig. 4C). At 2 mo of age, levels of TNF $\alpha$ and IL-1 $\beta$ were consistently greater in the mPFC than in the NAc or VTA. Instead, at 2224 mo of age, levels of TNF $\alpha$ and IL-1 $\beta$ in the VTA were consistently greater than those observed in the NAc and mPFC of the same mouse.

To determine how these transcript level changes relate to local inflammation at the protein level, we again microdissected NAc and VTA tissue from 2 mo, 18 mo, and 22-24 mo old CX3CR $1^{E G F P /+}$ mice and used high sensitivity ELISA arrays to examine a panel of pro- and anti- inflammatory cytokines. This analysis revealed that multiple pro- and anti-inflammatory cytokines were found at higher concentrations in the VTA compared to the NAc at all ages examined (Fig. 4D and Fig. S2). These included TNF $\alpha$, IL-1 $\beta$, interleukin 6 (IL-6), interferon gamma (IFN $\gamma$ ), interleukin 10 (IL-10), and interleukin 5 (IL-5). In the VTA, TNF $\alpha$ and IL-1 $\beta$ were further modulated by age, showing significant increases in tissue concentration at 22-24 mo relative to 2 mo. Chemokine ligand 1 (CXCL1; KC/GRO) was found at similar levels across both regions and was not modulated by age. IL-12p70, interleukin 2 (IL-2), interleukin 4 (IL-4) were not detected in these samples. Collectively these analyses suggest the existence of elevated local inflammation within VTA that is further exacerbated during aging.

Aging induced changes in VTA microglia emerge by 13 months of age. Analyses so far indicate that VTA microglia undergo changes in phenotype prior to microglia in other basal ganglia 
nuclei during aging. To gain more insight into when these changes begin during the lifespan, we quantified microglial density and inflammatory factor production in 13-14 mo old mice. In 13 mo old $C X 3 C R 1^{E G F P /+}$ mice, significant increases in microglial density could already be detected within the VTA, whereas no significant changes were observed within the NAc (Fig. 5A,B). To specifically examine microglial production of inflammatory factors, we microdissected larger portions of midbrain, striatum, and cortex to allow FACS isolation of microglia prior to analysis of gene expression via digital droplet PCR (Fig. 5C-E). These experiments revealed that microglial expression of TNF $\alpha$ tended to be greater in the midbrain compared to the striatum and cortex at all ages examined. When comparing regional gene expression levels within individual mice, no significant differences across region were observed in 2 mo old mice (Fig. 5E). In contrast, in 14 mo old mice, midbrain microglia expressed significantly higher levels of TNF $\alpha$ transcript than striatal or cortical microglia in the same mouse. These analyses indicate that region-specific changes in microglial phenotype begin midway through the lifespan for mice, suggesting that chronic exposure to these "aged" microglia and a low-level inflammatory milieu throughout the rest of the lifespan could critically shape synaptic function and disease vulnerability of nearby neurons.

Similar aging-induced changes are evident in SNC microglia. Midbrain dopamine neurons are particularly vulnerable to functional decline and neurodegenerative disease during aging. The underlying causes of this vulnerability are still poorly understood. The observation of early increases in VTA microglial density coupled with increased production of inflammatory factors could contribute to increased susceptibility of nearby dopamine neurons. Although dopamine neurons in the VTA exhibit elevated disease susceptibility, dopamine neurons in the SNc are typically more vulnerable to damage and decline ${ }^{48}$. To explore whether similar, aging-induced changes in microglial phenotype are observed in the SNc, we examined microglial density and morphology within the SNc of $C X 3 C R 1^{E G F P /+}$ mice. Similar to observations in the VTA, microglial density in the SNc was significantly elevated at 18 mo and remained elevated at 22-24 mo (Fig. 6A and Fig. S3A). When normalized to observed densities in 2 mo old mice, the increases in microglial density in the SNc were of similar magnitude to those observed in the VTA (Fig. 6B).

Morphological analysis revealed that there was also an increase in microglial tissue coverage by $18 \mathrm{mo}$ in the SNc (Fig. 6C and Fig. S3B). Similar to observations in the NAc and VTA, this represented a roughly 1.2 fold increase in overall tissue coverage. Morphological abnormalities were also evident in the SNc (Fig. 6D and Fig. S3C). Frequency of microglial somas with large protrusions was roughly $5.7 \pm 2 \%$, similar to that observed in VTA (5.6 $\pm 2 \%$ ). There were also instances of large inclusions along cell processes. These were distant from the cell body, and, similar to the somatic protrusions, did not contain nuclear material and were usually filled with CD68. Qualitatively, these inclusions did not resemble phagocytic cups, which tend to appear more hollow and show a brilliant rim of EGFP ${ }^{49}$. These process protrusions were observed in roughly $4.5 \pm 2 \%$ of microglia in the NAc, $6.1 \pm 4 \%$ of microglia in the VTA, and $8.0 \pm 3 \%$ of microglia in the SNc.

One morphological abnormality that we observed appeared to be largely unique to the SNc; these were apparent "clusters" of microglial cells adjacent to or among the SNc dopamine neurons (Fig. 6E and Fig. S3D). Microglial clusters were observed in the SNc of most mice, but were only rarely observed in the VTA and were not observed in the NAc (Fig. 6F). Although these clusters appeared to contain many microglial cells, co-labeling with DAPI revealed that 
they sometimes only contained 3-4 microglia that had an elaborated, extensive membrane surface area (Fig. 6G and Fig. S3D). There were no obvious indications that these clusters were associated with dying cells, as no condensed chromatin or pyknotic nuclei were observed within these structures. However, these clustered microglia did contain abundant CD68+ lysosomes, suggesting degradation of engulfed material. There were no obvious differences between dopamine neurons near to these clusters and more distant from these clusters. Collectively, these analyses indicate that changes in the SNc microglial population during aging are largely similar to those observed in VTA microglia, with the presence of microglial "clusters" representing an additional, unique change in microglial phenotype in this brain region.

Aging induced changes in VTA/SNc microglia precede systemic inflammation, local changes in astrocyte abundance and parallel early loss of neurons. Systemic inflammation generally increases with aging and cytokines produced in the periphery can penetrate the blood-brain barrier and modulate function of cells within the $\mathrm{CNS}^{50}$. Regional differences in this CNS penetration of cytokines could potentially contribute to these early changes in VTA/SNc microglial phenotype. To determine whether this might be case, we measured serum levels of inflammatory signaling factors using MesoScale ELISA based cytokine arrays in 2, 18, and 2224 mo old $C X 3 C R 1^{E G F P /+}$ mice. This analysis revealed that a number of pro-inflammatory signaling factors, such as IFN $\gamma$, IL-6, and TNF $\alpha$ were significantly increased during aging (Fig. S4). Levels of several factors that have a mix of pro- and anti-inflammatory functions or largely anti-inflammatory functions were also elevated during aging, including IL-10, IL-2, and CXCL1. Other factors such as IL-1 $\beta$, IL-4, and IL- 5 were detected in serum but did not show any significant changes at the ages we sampled. In all cases where serum cytokines were observed to increase during aging, posthoc analyses revealed that these increases were not significant until 24 mo of age. Together, these data support that systemic levels of inflammation increase during aging, but suggest that changes in microglial phenotype and expansion of the microglial population occur prior to detectible changes in organism-wide inflammation.

Microglia and astrocytes can regulate one another's attributes in multiple contexts ${ }^{51}$. Astrocytes also make critical contributions to tissue homeostasis, produce inflammatory factors, and can proliferate and change phenotype in response to insults and challenges ${ }^{42}$. In young adult mice, we found that local abundance of microglia was tightly correlated with local density of astrocytes $^{29}$. To explore whether regional differences in how astrocytes respond to aging could contribute to regional differences in how microglia respond to aging, we examined astrocytes in young adult and aging ALDH1L1-EGFP mice. Quantification of cell density revealed astrocyte abundance remained relatively stable in the NAc and VTA between 2 mo and 24 mo of age (Fig. 7A-B). There was a trend toward decreased astrocytes abundance in the NAc at 24 mo, but this did not reach significance. Examination of high magnification images of ALDH1L1-EGFP mice indicate that, qualitatively, astrocytes largely maintain their morphological characteristics, including interaction with local blood vessels (Fig. S5A) and do not exhibit clear somatic protrusions or cell process inclusions. Together, these observations indicate that increases in VTA/SNc microglial density during aging are not caused by parallel increases within the astrocyte population.

Microglia respond to cell death of nearby neurons with numerous changes in cell attributes. Because dopamine neurons are more susceptible to functional decline, early loss of these vulnerable neurons could potentially contribute to regional differences in microglial responses to aging. To explore this possibility, we used two approaches to quantify the 
abundance of dopamine neurons in the VTA and SNc at 2, 18, and 24 mo in CX3CR $1^{E G F P /+}$ mice (Fig. 7C,D). Quantification of the total number of dopamine neurons in stereological matched brain sections (Fig. S5B) revealed trends toward reduced numbers of dopamine neurons at 18 and 24 mo but these were not significant (Fig. 7E). Quantification of cell density revealed decreases in dopamine neuron cell density that were significant only when pooling data across the VTA and SNc (Fig. 7F). Together, these data indicate that loss of dopamine neurons is relatively minor at the ages examined. Glutamatergic and GABAergic neurons are also present within the VTA and SNc ${ }^{48,52}$. To check for cell death within these cell populations we also quantified abundance of NeuN+TH- neurons. In general, these neurons were less abundant in the SNc than in the VTA (Fig. 7E,F). Similar to dopamine neurons, NeuN+TH- neurons showed trends toward reduced total number of neurons and significant reductions in cell density when pooling across the VTA and SNc (Fig. 7E,F). Collectively, these analyses suggest that neuron loss in the VTA/SNc is not extensive at the ages examined and that increases in VTA/SNc microglial proliferation and production of inflammatory factors likely precede rather than follow substantial neuronal loss in these brain regions.

CX3CR1 deletion and microglial ablation and repopulation modulate region-specific microglial aging responses. Signaling through the CX3CR1 (fractalkine) can modulate microglial properties and microglia that lack CX3CR1 have been shown to be beneficial or detrimental depending on context ${ }^{53,54}$. In addition, patterns of microglial gene expression associated with aging were more pronounced in mice lacking CX3CR1 and dopamine neuron loss more severe in MPTP-treated CX3CR1 lacking mice ${ }^{55,56}$. To determine whether signaling through this receptor could influence region-specific changes in microglial aging, we compared age-associated changes in microglial density in wildtype C57Bl6 mice and CX3CR1 ${ }^{\text {EGFP/EGFP }}$ (CX3CR1-KO) mice (Fig. 8A,B and Fig. S6A,B). Patterns of microglial abundance in these mice largely mirrored those observed in $C X 3 C R 1^{E G F P /+}$ mice. NAc microglia did not show significant changes in density between $2 \mathrm{mo}$ and $18 \mathrm{mo}$ of age in either C57Bl6 wildtype or CX3CR1-KO mice (Fig. $\mathbf{8 C , D ) . ~ V T A ~ m i c r o g l i a ~ i n s t e a d ~ s h o w e d ~ t r e n d s ~ t o w a r d ~ s i g n i f i c a n t ~ i n c r e a s e s ~ i n ~ d e n s i t y ~ i n ~ w i l d t y p e ~}$ mice and significant increases in density by 18 mo in CX3CR1-KO mice (Fig. 8C,D), highlighting consistency of this region-specific response of microglia to aging. Normalizing values to the mean density of microglia in each region at $2 \mathrm{mo}$, revealed that the relative increase in VTA microglial density at 18 mo was larger in CX3CR1-KO mice compared to wildtype mice. These findings suggest that signaling through the CX3CR1 receptor plays a role in shaping region specific responses of microglia to aging. The relationship between microglial density in the NAc and VTA of individual 18mo old mice and the ratio of VTA:NAc microglial density was relatively consistent across genotypes (Fig. S6F-H). This could be due to the fact that NAc microglial density in 18mo CX3CR1-KO mice also appeared slightly elevated compared to wildtype mice (Fig. 8E), although this did not reach significance. Hence the effects of signaling through CX3CR1 on microglial aging may be apparent throughout the basal ganglia but be more accentuated in regions prone to early microglial aging.

Microglia are dependent on activation of the colony stimulating factor 1 receptor (CSFR1) and can be ablated from the CNS via chronic pharmacological antagonism of this receptor $^{57}$. Following microglial ablation in this manner, removal of CSFR1 antagonism will allow microglia to repopulate the $\mathrm{CNS}^{58}$. Previous studies have shown that ablation and repopulation of microglia in aging mice can partially reverse aging-induced changes observed in these cells and improve cognition ${ }^{26,59}$. However, whether microglial ablation and repopulation 
can mitigate the early aging phenotypes exhibited by microglia in specific brain regions has not been explored. To evaluate this, we fed 13-20 mo old CX3CR1 $1^{E G F P /+}$ mice on PLX5622 or control diet for 21 days. PLX5622 resulted in an $91 \pm 0.2 \%$ and $84 \pm 1 \%$ reduction in microglial numbers in the NAc and VTA respectively (Fig. 8F,G and Fig. S6F). Subsequent removal of the PLX5622 diet for 21 days resulted in microglial repopulation in both regions. Within the NAc, microglial density in ablated/repopulated mice was comparable to that in control mice (Fig. 8G). Instead, in the VTA, microglial density in repopulated mice was significantly lower than that observed in control mice (Fig. 8H). Normalizing these values to the mean density observed in each region in 2 mo old mice revealed that in control 13-20 mo mice, VTA microglial density was roughly 1.4 fold greater than that observed in 2 mo old mice (Fig. 8I). In 13-20 mo ablated/repopulated mice, however, VTA microglial density was equivalent to that observed in 2 mo old mice. When comparing density of microglia across brain regions within individual mice (Fig. S6G), VTA microglial density was consistently well below that observed in the NAc of the same mouse following microglial ablation/repopulation, similar to what is observed in 2 mo old mice. In addition the ratio of NAc to VTA microglia within individual ablated/repopulated mice did not differ significantly from that observed in 2 mo old mice (Fig. S6H). Together, these results suggest that microglial ablation and repopulation during aging can, at least temporarily, mitigate region-specific expansion of the VTA microglial population.

\section{DISCUSSION}

\section{Causes of microglial proliferation during aging}

Here we demonstrate that the onset of microglial proliferation during aging varies widely across brain regions. Microglia are highly proliferative during early postnatal development as they colonize the CNS ${ }^{40,49}$ after which they reach a steady-state in adulthood and cell turnover is relatively minimal ${ }^{7}$. Nonetheless, numerous stimuli can cause microglia to mount a substantial proliferative response throughout the lifespan including acute brain injury, disease processes, and repopulation of microglia after microglial ablation ${ }^{1,2,58}$. Studies disagree about the impact of aging on microglial abundance. Several groups have previously reported that normal aging is accompanied by increases in microglial number in cortex ${ }^{22,39}$, hippocampus ${ }^{60}$, and CNS white matter tracts ${ }^{33,37}$. Most of these observations focus on microglial abundance late in life (22-24 mo in mice or rats) and are not able to distinguish whether these increases resulted from microglial proliferation or infiltration of peripheral monocytes that then acquire microglial-like attributes. Here, we show that local increases in microglia during aging can occur as early as middle age (13-14 mo) (Fig. 1) and that the magnitude of increase attained by late age in the VTA and SNc is much larger than that reported in cortex and on par with that reported in hippocampus and white matter. Further, by conditionally "tagging" microglia present in young adulthood via expression of DTR, we show that this local expansion of the microglial population is chiefly driven by proliferation of resident CNS microglia (Fig. 2 and Fig. S1). Several studies have reported no change in substantia nigra ${ }^{33}$, progressive decreases in substantia nigra ${ }^{61}$, or transient decreases in VTA and SNc microglial number during aging ${ }^{62}$. These studies generally rely on Iba1 immunostaining, which may be more difficult to accurately quantify than genetically-encoded fluorescent markers. Use of 1 month "young adult” comparisons likely skews data, as microglia in the basal ganglia are overproduced during this window before being refined down to adult levels by $2 \mathrm{mo}$ of age $\mathrm{e}^{49}$. Finally, microglial density varies dramatically 
across the substantia nigra pars compacta and pars reticulata ${ }^{29}$, complicating interpretation of how microglial density changes with age in studies that do not distinguish between these subdivisions of the substantia nigra. We use Iba1 as well as genetically encoded fluorophore and genetic tagging to demonstrate increases in microglial density in multiple mouse lines, revealing the robustness of early microglial proliferation and population expansion in the VTA and SNc during aging.

While the causes of microglia proliferation sometimes appear obvious - a need to populate the CNS during development, responding to an acute injury to contain the spread of damage, removing dying cells during degenerative disease - the causes of microglial proliferation in aging are less clear. We did not detect obvious increases in dying cells (via pyknotic DAPI+ nuclei) in regions where microglia exhibit local proliferation. Furthermore, microglia in proliferative regions did not exhibit obvious phagocytotic cups. We did not detect substantial neuron loss in the VTA/SNc by 18mo of age (Fig. 7), in agreement with other reports 62,63 , suggesting that early increases in microglial abundance are unlikely to be caused by neuronal death in these brain regions. Although systemic inflammation can promote microglial proliferation $^{64}$, we did not detect increases in plasma levels of inflammation until 24mo of age, well after increased VTA/SNc microglial proliferation. Even the local inflammation we observe within the VTA/SNc at ealier time points (13-14 mo via mRNA analysis) is likely relatively mild compared to the inflammatory milieu observed following acute infection, injury, or during degenerative disease ${ }^{43}$. Finally, astrocytes can also proliferate in response to inflammatory signaling and we did not observe significant increases in the number of these cells. These observations suggest that such chronic, low-level inflammation may be sufficient to raise vulnerability of local synapses and neurons but may not be the major driver of microglial proliferation in healthy aging.

Although we did not observe dying cells and microglial phagocytic cups, we did observe microglial morphological abnormalities suggestive of increased degradative burdens within these cells during aging. These included somatic protrusions and cell process inclusions in some cells that were filled with CD68+lysosomes. They also included clusters of microglia within the SNc that showed abundant CD68 labeling but no pyknotic nuclei. Microglial proliferation could be necessary to support some aspect of this increased degradative burden. Increases in microglial number in the cortex of aging mice were modulated by loss of sensory input to these regions ${ }^{39}$. These findings suggest that expansion of the microglial population can be influenced by changing patterns of local neuronal activity during aging. Ample human and rodent behavioral data support declining dopamine-dependent cognitive and motor performance during aging ${ }^{63,65-}$ ${ }^{70}$, indicating that patterns of local neuronal activity are likely to be shifting within the VTA/SNc during aging. Very limited slice electrophysiology studies in aging mice also suggest altered excitability of these neurons during aging ${ }^{71}$. Mounting evidence from young adult mice indicates that microglia are equipped to sense and respond to changes in ongoing neuronal activity ${ }^{14,15}$. An important area of future investigation will be to elucidate the relationship between local changes in neuronal activity and local microglial responses to aging; does one cause the other or do both changes reinforce and amplify one another?

Chronic local inflammation as a consequence of microglial proliferation during aging? During aging, increases in both systemic and CNS inflammation have been observed across species $^{43,64,72}$. We provide evidence that regional differences in protein levels of inflammatory factors may be present in young adulthood and that the time course and magnitude of increases 
in local inflammation during aging are not uniform across the brain. This indicates that neurons in the VTA (and likely SNc) are exposed to chronic low-level inflammation throughout the lifespan with regional differences accentuating with age. Microglia and astrocytes are believed to be major contributors to CNS inflammation ${ }^{42,43,73}$. Although we cannot attribute discrete amounts of local inflammation to one specific cell population, several observations suggest that microglia play a central role in regulating these local increases in VTA inflammation during aging. First, the time course of microglial proliferation in the VTA is tightly aligned with the time course of increasing levels of TNF $\alpha$ and IL-1 $\beta$ transcript in this brain region. Furthermore, region-specific, age-associated increases in TNF $\alpha$ and IL-1 $\beta$ transcript were observed within midbrain microglia as early as $14 \mathrm{mo}$ of age. Finally, no parallel increases in astrocyte density were observed and published transcriptome data from aging astrocytes suggests that TNF $\alpha$ and IL-1 $\beta$ are not expressed at high levels by these cells in young or aged mice ${ }^{74,75}$. However, expression of many other genes does change within astrocytes during aging in a region-specific manner ${ }^{74}$, and microglia can induce astrocyte phenotypes that are detrimental to neurons ${ }^{19}$. Hence, our data do not preclude that changes in both these glial cell populations shape the degree to which the local environment is neuroprotective or neurotoxic.

Microglia have been implicated in death of dopamine neurons during Parkinson's Disease (PD) progression ${ }^{43,72}$ and substantial increases in local inflammation may play a role in this process. Elevated inflammation such as that induced by LPS challenge ${ }^{76}$ leads to loss of dopamine neurons and blocking TNF $\alpha$ signaling is protective in models of $\mathrm{PD}^{77}$. However, the aging-induced increases in inflammation that we report here are likely well below those experienced during acute infection, acute injury or late stages of degenerative disease. Consistent with this idea, we observe relatively little neuronal loss within the VTA and SNc by 18 and 2224 mo of age. However, low levels of inflammation are not necessarily benign. Synapse loss and synapse dysfunction are linked to cognitive deficits during aging and they also characterize presymptomatic stages of neurodegenerative disease ${ }^{78-81}$, suggesting that synaptic decline may contribute to increased disease susceptibility with increasing age. Several observations indicate that inflammatory signaling can critically influence synapse integrity and synapse function during aging. Decreased inflammation is correlated with improved cognition during aging ${ }^{82}$. Lifestyle manipulations such as exercise and low-fat diet that alter microglial phenotype and reduce inflammation are also associated with improved cognition ${ }^{73}$. Moreover, microglial TNF $\alpha$ has been shown to influence presynaptic probability of release and insertion/removal of postsynaptic AMPA receptors at glutamatergic synapses ${ }^{83}$. TNF $\alpha$ can also impact GABA receptor insertion/removal from inhibitory synapse, placing this molecule in a position to influence the overall balance of excitatory and inhibitory input to neurons. This excitatory / inhibitory balance is known to shift during aging, resulting in neuronal hyperexcitability that precedes neuronal loss. IL-1 $\beta$ has also been shown to impact the ability of LTP to occur ${ }^{84}$.

Collectively, these data suggest that perturbed synaptic function is a likely outcome of early elevations in inflammation within the VTA. The observation of age-dependent decline in dopamine-dependent cognition and movement in humans ${ }^{65-67,85}$, non-human primates ${ }^{86}$, and rodents ${ }^{63,70}$ support the idea of perturbed synaptic function within this circuitry. Although CNSwide microglial ablation and repopulation improved performance in some cognitive tests in aging mice, these studies did not report decreases in inflammation as a result of this manipulation ${ }^{26,59}$. However, inflammation was only examined in hippocampus or brain wide and inflammatory signaling within specific circuit microenvironments may play a stronger role in shaping cognitive function than overall ambient CNS inflammation. Although this seems to 
indicate that inflammation is certainly detrimental, as the field moves forward, we must still be open to the idea that inflammatory signaling also plays a role in some beneficial functions of microglia and astrocytes.

How do region-specific responses of microglia to aging relate to disease susceptibility? As noted above, chronic local inflammation beginning in midlife could contribute to the increased disease susceptibility of dopamine neurons. Some epidemiological studies suggest links between inflammation and prevalence of neurodegenerative disease; long term use of nonsteroidal anti-inflammatory medication reduced the risk of Alzheimer's and PD by almost $50 \%{ }^{87-89}$. Accumulation of protein aggregates with aging and specific mutations in aggregateprone proteins like $\alpha$-synuclein are linked to risk of degenerative disease ${ }^{90}$. Microglial process motility and surveillance of the surrounding microenvironment decreases with aging in the cortex and in vitro experiments also suggest declining phagocytic capacity of these cells with age $^{22,73}$. Although we did not directly assess process motility or phagocytosis, the observation of changes in microglial tissue coverage and increased "gaps" between microglial processes in VTA and SNc by 18 months suggest that microglial capacity to support local tissue homeostasis and aggregate clearance is likely. Mice that are lacking CX3CR1 show more extensive neuronal loss in a mouse model of $\mathrm{PD}^{56}$. We observed greater fold-increases in local microglial density with aging in CX3CR1-KO mice, suggesting that signaling pathways regulating local microglial responses to aging also shape disease susceptibility. Finally, microglia respond to many of the environmental risk factors that increase susceptibility to PD including traumatic brain inury and exposure to toxins ${ }^{3,91,92}$. Together these observations suggest that the early changes we observe in VTA and SNc microglia during aging lay a foundation of heightened vulnerability for nearby dopamine neurons that will intersect with other genetic and environmental risk factors to determine overall disease risk.

Two other factors that shape disease risk are worth exploring. First, men are at higher risk of developing PD than women ${ }^{93}$. Although male-female differences in microglial aging have been reported ${ }^{94-96}$, we did not observe any obvious male-female differences in the regionspecific microglial changes that we report here (Fig. S7). Further research would be needed to unequivocally determine whether sex influences the degree of region-specific microglial responses to aging. Second, SNc dopamine neurons are more vulnerable to PD than VTA dopamine neurons, although both are eventually lost as disease progresses ${ }^{48,97}$. VTA and SNc microglia are much more similar to one another than they are to microglia in other basal ganglia nuclei or cortex ${ }^{29}$. However, can differences in how VTA and SNc microglia respond to aging be linked to differential susceptibility of VTA and SNc neurons to disease? Our results indicate that increases in VTA and SNc microglial density during aging show a very similar magnitude and time course. They also show similar increases in tissue coverage, somatic CD68+ protrusions, and cell process inclusions. One morphological abnormality that was primarily observed in the SNc was the presence of microglial "clusters" among and adjacent to SNc dopamine neurons. These microglia clusters resemble "multinucleated giant cells (MGCs)" that have been reported in the context of presymptomatic amyotrophic lateral sclerosis ${ }^{98}$, HIV-induced dementia ${ }^{99}$, macaque and rat models of $\mathrm{PD}^{72}$, and in white matter tracts of aged (21 mo) mice ${ }^{33}$. Similar to our observations in the aging SNc, these studies report that MGCs rarely contained obvious pyknotic nuclei and that they tended to be arranged in circular fashion with nuclei around the periphery. In vitro experiments suggest that microglial MGCs are 2-4 fold more phagocytic and that their formation can be induced by stimulation with phagocytic challenges such as by 
amyloid- $\beta$ and $\alpha$-synuclein, as well as by inflammatory stimuli such as LPS, TNF $\alpha$, and IFN $\gamma^{100}$. While there is still little information available about microglial MGCs in vivo, their elevated presence in the SNc during aging suggests that this region is experiencing greater inflammatory signaling, phagocytic demand, and/or elevated $\alpha$-synuclein than other nearby regions including the VTA. Additional research will be needed to determine if this is the case and if subtle differences in VTA and SNc microglial responses to aging further elevate the vulnerability of SNc dopamine neurons.

\section{CONCLUSIONS}

Here, we provide evidence that microglial responses to aging are highly variable within basal ganglia circuits. In the VTA, microglia show increased proliferation and production of inflammatory factors that begin as early at 13-14 mo of age, which for mice represents midlife. Although the ability of microglia and inflammation to shape neuronal health during aging have been appreciated, the degree of local precision with which these cellular and molecular features of CNS aging can be regulated and the early timing of their onset in some regions has not been well appreciated. The "pockets" of inflammation that form in the VTA likely inform local synaptic function and contribute to the enhanced disease vulnerability of dopamine neurons. A challenge for future research will be to understand how premature VTA/SNc microglial responses to aging intersect with other risk factors to shape overall vulnerability of local neurons to decline and disease. Moreover, understanding the degree to which these local microglial responses to aging are driven by the distinct phenotype that VTA/SNc microglia exhibit in young adulthood versus unique changes in the local microenvironment during aging will aid in more effective targeting of therapeutic interventions. Most likely there is a complex interplay of both cell-intrinsic and local environmental factors at work. There are numerous aspects of the local brain environment that we did not probe and that could contribute to unique microglial aging in these brain regions. These include ambient levels of reactive oxygen species, local differences in blood-brain barrier integrity and transient infiltration of T cells, which can program microglia, and local myelin integrity, among others. Importantly, we observe two manipulations that can modulate the local microglial response to aging, indicating that multiple strategies may be available for harnessing these important cells to preserve neuronal health and function throughout the lifespan.

Acknowledgments: This work was supported by the National Institute on Drug Abuse Intramural Research Program (L.M.D), the National Institute on Aging Intramural Research Program (N.G.), start-up funds from the David Geffen School of Medicine at UCLA (L.M.D.) and the Glen Foundation for Medical Research and American Federation for Aging Research Grant for Junior Faculty (L.M.D.). The authors thank Preethi Gopal, Chloe Noe, Sissi Palma Ribeiro, and Serena Scognamiglio for their contributions to early histology experiments and analysis. The authors thank the Johns Hopkins Bayview Immunomics Core (supported by NIAMS P30 AR-070254), Raffaello Cimbro, and the UCLA Eli and Edythe Broad Center of Regenerative Medicine and Stem Cell Research Flow Cytometry Core for assistance with FACSbased experiments. The authors thank the UCLA Eli and Edythe Broad Center of Regenerative Medicine and Stem Cell Research Microscopy Core for access to confocal microscopes. The authors thank Plexxikon for supplying the CSFR1 antagonist PLX5622. The authors thank Ari Schaler, Fanny Etienne, and Daniel Gray for help with manuscript editing. 
Author Contributions: Conceptualization, L.M.D; Methodology, L.M.D, E.N.M., D.L., D.T., N.H.G., and D.R.S.; Investigation: L.M.D, E.N.M., D.L., D.T., K.H., S.S., L.M., H.S., and R.M.; Formal Analysis, L.M.D, E.N.M., D.L., D.T., K.H., S.S., L.M., and H.S.; Visualization, L.M.D and E.N.M.; Writing, L.M.D.; Funding Acquisition, L.M.D, N.H.G, and D.R.S; Supervision, L.M.D, N.H.G, and D.R.S

\section{REFERENCES}

1. Wolf, S. A., Boddeke, H. W. G. M. \& Kettenmann, H. Microglia in Physiology and Disease. Annu. Rev. Physiol. (2016). doi:10.1146/annurev-physiol-022516-034406

2. Salter, M. W. \& Stevens, B. Microglia emerge as central players in brain disease. Nature Medicine (2017). doi:10.1038/nm.4397

3. Ransohoff, R. M. \& Perry, V. H. Microglial Physiology: Unique Stimuli, Specialized Responses. Annu. Rev. Immunol. 27, 119-45 (2009).

4. Davalos, D. et al. ATP mediates rapid microglial response to local brain injury in vivo. Nat. Neurosci. (2005). doi:10.1038/nn1472

5. Nimmerjahn, A., Kirchhoff, F. \& Helmchen, F. Neuroscience: Resting microglial cells are highly dynamic surveillants of brain parenchyma in vivo. Science (80-. ). (2005). doi:10.1126/science.1110647

6. Li, Q. \& Barres, B. A. Microglia and macrophages in brain homeostasis and disease. Nature Reviews Immunology (2018). doi:10.1038/nri.2017.125

7. Kierdorf, K. \& Prinz, M. Microglia in steady state. Journal of Clinical Investigation (2017). doi:10.1172/JCI90602

8. Wu, Y., Dissing-Olesen, L., MacVicar, B. A. \& Stevens, B. Microglia: Dynamic Mediators of Synapse Development and Plasticity. Trends Immunol. 36, 605-613 (2015).

9. Werneburg, S., Feinberg, P. A., Johnson, K. M. \& Schafer, D. P. A microglia-cytokine axis to modulate synaptic connectivity and function. Current Opinion in Neurobiology (2017). doi:10.1016/j.conb.2017.10.002

10. York, E. M., Bernier, L. P. \& MacVicar, B. A. Microglial modulation of neuronal activity in the healthy brain. Developmental Neurobiology (2018). doi:10.1002/dneu.22571

11. Nguyen, P. T. et al. Microglial Remodeling of the Extracellular Matrix Promotes Synapse Plasticity. Cell (2020). doi:10.1016/j.cell.2020.05.050

12. Reemst, K., Noctor, S. C., Lucassen, P. J. \& Hol, E. M. The Indispensable Roles of Microglia and Astrocytes during Brain Development. Front. Hum. Neurosci. 10, 10.3389/fnhum.2016.00566 (2016).

13. Lewitus, G. M. et al. Microglial TNF- $\alpha$ Suppresses Cocaine-Induced Plasticity and Behavioral Sensitization. Neuron (2016). doi:10.1016/j.neuron.2016.03.030

14. Cserép, C. et al. Microglia monitor and protect neuronal function through specialized somatic purinergic junctions. Science (80-. ). (2020). doi:10.1126/science.aax6752

15. Badimon, A. et al. Negative feedback control of neuronal activity by microglia. Nature (2020). doi:10.1038/s41586-020-2777-8

16. Chen, Z. \& Trapp, B. D. Microglia and neuroprotection. Journal of Neurochemistry (2016). doi:10.1111/jnc.13062

17. DiSabato, D. J., Quan, N. \& Godbout, J. P. Neuroinflammation: the devil is in the details. J. Neurochem. (2016). doi:10.1111/jnc.13607 
18. Spittau, B. Aging microglia-phenotypes, functions and implications for age-related neurodegenerative diseases. Front. Aging Neurosci. (2017). doi:10.3389/fnagi.2017.00194

19. Liddelow, S. A. et al. Neurotoxic reactive astrocytes are induced by activated microglia. Nature (2017). doi:10.1038/nature21029

20. Clarke, L. E. et al. Normal aging induces A1-like astrocyte reactivity. Proc. Natl. Acad. Sci. U. S. A. (2018). doi:10.1073/pnas.1800165115

21. Norden, D. M., Muccigrosso, M. M. \& Godbout, J. P. Microglial priming and enhanced reactivity to secondary insult in aging, and traumatic CNS injury, and neurodegenerative disease. Neuropharmacology (2015). doi:10.1016/j.neuropharm.2014.10.028

22. Hefendehl, J. K. et al. Homeostatic and injury-induced microglia behavior in the aging brain. Aging Cell (2014). doi:10.1111/acel.12149

23. Damani, M. R. et al. Age-related alterations in the dynamic behavior of microglia. Aging Cell (2011). doi:10.1111/j.1474-9726.2010.00660.x

24. Hong, S. et al. Complement and microglia mediate early synapse loss in Alzheimer mouse models. Science (80-. ). (2016). doi:10.1126/science.aad8373

25. Stephan, A. H. et al. A Dramatic Increase of C1q Protein in the CNS during Normal Aging. J. Neurosci. (2013). doi:10.1523/jneurosci.1333-13.2013

26. Elmore, M. R. P. et al. Replacement of microglia in the aged brain reverses cognitive, synaptic, and neuronal deficits in mice. Aging Cell (2018). doi:10.1111/acel.12832

27. Hickman, S., Izzy, S., Sen, P., Morsett, L. \& El Khoury, J. Microglia in neurodegeneration. Nat. Neurosci. 21, 1359-1369 (2018).

28. Sala Frigerio, C. et al. The Major Risk Factors for Alzheimer's Disease: Age, Sex, and Genes Modulate the Microglia Response to A $\beta$ Plaques. Cell Rep. (2019).

doi:10.1016/j.celrep.2019.03.099

29. De Biase, L. M. et al. Local Cues Establish and Maintain Region-Specific Phenotypes of Basal Ganglia Microglia. Neuron 95, 341-356 (2017).

30. Grabert, K. et al. Microglial brain regionâ 'dependent diversity and selective regional sensitivities to aging. Nat. Neurosci. (2016). doi:10.1038/nn.4222

31. Ayata, P. et al. Epigenetic regulation of brain region-specific microglia clearance activity. Nat. Neurosci. (2018). doi:10.1038/s41593-018-0192-3

32. de Haas, A. H., Boddeke, H. W. G. M. \& Biber, K. Region-specific expression of immunoregulatory proteins on microglia in the healthy CNS. Glia (2008). doi:10.1002/glia.20663

33. Hart, A. D., Wyttenbach, A., Hugh Perry, V. \& Teeling, J. L. Age related changes in microglial phenotype vary between CNS regions: Grey versus white matter differences. Brain. Behav. Immun. (2012). doi:10.1016/j.bbi.2011.11.006

34. O’Koren, E. G. et al. Microglial Function Is Distinct in Different Anatomical Locations during Retinal Homeostasis and Degeneration. Immunity (2019). doi:10.1016/j.immuni.2019.02.007

35. Stowell, R. D. et al. Cerebellar microglia are dynamically unique and survey Purkinje neurons in vivo. Dev. Neurobiol. (2018). doi:10.1002/dneu.22572

36. Gunner, G. et al. Sensory lesioning induces microglial synapse elimination via ADAM10 and fractalkine signaling. Nat. Neurosci. (2019). doi:10.1038/s41593-019-0419-y

37. Safaiyan, S. et al. Age-related myelin degradation burdens the clearance function of microglia during aging. Nat. Neurosci. (2016). doi:10.1038/nn.4325

38. Hayashi, Y. et al. Diurnal Spatial Rearrangement of Microglial Processes through the 
Rhythmic Expression of P2Y12 Receptors. J. Neurol. Disord. 1, doi: 10.4172/23296895.1000120 (2013).

39. Tremblay, M. Ė., Zettel, M. L., Ison, J. R., Allen, P. D. \& Majewska, A. K. Effects of aging and sensory loss on glial cells in mouse visual and auditory cortices. Glia (2012). doi:10.1002/glia.22287

40. Ginhoux, F., Lim, S., Hoeffel, G., Low, D. \& Huber, T. Origin and differentiation of microglia. Front. Cell. Neurosci. 7, (2013).

41. Baufeld, C., O’Loughlin, E., Calcagno, N., Madore, C. \& Butovsky, O. Differential contribution of microglia and monocytes in neurodegenerative diseases. Journal of Neural Transmission (2018). doi:10.1007/s00702-017-1795-7

42. Salas, I. H., Burgado, J. \& Allen, N. J. Glia: victims or villains of the aging brain? Neurobiology of Disease (2020). doi:10.1016/j.nbd.2020.105008

43. Lucin, K. M. \& Wyss-Coray, T. Immune Activation in Brain Aging and Neurodegeneration: Too Much or Too Little? Neuron (2009). doi:10.1016/j.neuron.2009.08.039

44. Skaper, S. D., Facci, L., Zusso, M. \& Giusti, P. An inflammation-centric view of neurological disease: Beyond the neuron. Frontiers in Cellular Neuroscience (2018). doi:10.3389/fncel.2018.00072

45. Sochocka, M., Diniz, B. S. \& Leszek, J. Inflammatory Response in the CNS: Friend or Foe? Molecular Neurobiology (2017). doi:10.1007/s12035-016-0297-1

46. Primiani, C. T. et al. Coordinated gene expression of neuroinflammatory and cell signaling markers in dorsolateral prefrontal cortex during human brain development and aging. PLoS One (2014). doi:10.1371/journal.pone.0110972

47. Lu, T. et al. Gene regulation and DNA damage in the ageing human brain. Nature (2004). doi:10.1038/nature02661

48. Brichta, L. \& Greengard, P. Molecular determinants of selective dopaminergic vulnerability in Parkinson's disease: An update. Front. Neuroanat. (2014). doi:10.3389/fnana.2014.00152

49. Hope, K. T., Hawes, I. A., Moca, E. N., Bonci, A. \& De Biase, L. M. Maturation of the microglial population varies across mesolimbic nuclei. Eur. J. Neurosci. (2020). doi:10.1111/ejn.14740

50. Kennedy, R. H. \& Silver, R. Neuroimmune Signaling: Cytokines and the CNS. in Neuroscience in the 21st Century (2015). doi:10.1007/978-1-4614-6434-1_174-1

51. Vainchtein, I. D. \& Molofsky, A. V. Astrocytes and Microglia: In Sickness and in Health. Trends in Neurosciences (2020). doi:10.1016/j.tins.2020.01.003

52. Morales, M. \& Margolis, E. B. Ventral tegmental area: Cellular heterogeneity, connectivity and behaviour. Nature Reviews Neuroscience (2017). doi:10.1038/nrn.2016.165

53. Mecca, C., Giambanco, I., Donato, R. \& Arcuri, C. Microglia and aging: The role of the TREM2-DAP12 and CX3CL1-CX3CR1 Axes. International Journal of Molecular Sciences (2018). doi:10.3390/ijms19010318

54. Limatola, C. \& Ransohoff, R. M. Modulating neurotoxicity through CX3CL1/CX3CR1 signaling. Frontiers in Cellular Neuroscience (2014). doi:10.3389/fncel.2014.00229

55. Gyoneva, S. et al. Cx3cr1-deficient microglia exhibit a premature aging transcriptome. Life Sci. Alliance (2019). doi:10.26508/lsa.201900453

56. Cardona, A. E. et al. Control of microglial neurotoxicity by the fractalkine receptor. Nat. 
Neurosci. (2006). doi:10.1038/nn1715

57. Renee, M. et al. CSF1 receptor signaling is necessary for microglia viability, which unmasks a cell that rapidly repopulates the microglia- depleted adult brain. Neuron (2015).

58. Huang, Y. et al. Repopulated microglia are solely derived from the proliferation of residual microglia after acute depletion. Nat. Neurosci. 21, 530-540 (2018).

59. O’Neil, S. M., Witcher, K. G., McKim, D. B. \& Godbout, J. P. Forced turnover of aged microglia induces an intermediate phenotype but does not rebalance CNS environmental cues driving priming to immune challenge. Acta Neuropathol. Commun. (2018). doi:10.1186/s40478-018-0636-8

60. Hovens, I. B. et al. Postoperative cognitive dysfunction and microglial activation in associated brain regions in old rats. Neurobiol. Learn. Mem. (2015). doi:10.1016/j.nlm.2014.11.009

61. Sharaf, A., Krieglstein, K. \& Spittau, B. Distribution of microglia in the postnatal murine nigrostriatal system. Cell Tissue Res. (2013). doi:10.1007/s00441-012-1537-y

62. Shaerzadeh, F. et al. Microglia senescence occurs in both substantia nigra and ventral tegmental area. Glia (2020). doi:10.1002/glia.23834

63. Noda, S., Sato, S., Fukuda, T., Tada, N. \& Hattori, N. Aging-related motor function and dopaminergic neuronal loss in C57BL/6 mice. Mol. Brain (2020). doi:10.1186/s13041020-00585-6

64. Cunningham, C. Microglia and neurodegeneration: The role of systemic inflammation. Glia (2013). doi:10.1002/glia.22350

65. Bäckman, L., Lindenberger, U., Li, S. C. \& Nyberg, L. Linking cognitive aging to alterations in dopamine neurotransmitter functioning: Recent data and future avenues. Neuroscience and Biobehavioral Reviews (2010). doi:10.1016/j.neubiorev.2009.12.008

66. Sarter, M., Albin, R. L., Kucinski, A. \& Lustig, C. Where attention falls: Increased risk of falls from the converging impact of cortical cholinergic and midbrain dopamine loss on striatal function. Experimental Neurology (2014). doi:10.1016/j.expneurol.2014.04.032

67. Visser, J. E. \& Bloem, B. R. Role of the basal ganglia in balance control. Neural Plasticity (2005). doi:10.1155/NP.2005.161

68. Cerebral Cortex: Neurodegenerative and age-related changes in structure and function of cerebral cortex. (Kluwer Academic / Plenum Publishers, 1999).

69. Froudist-Walsh, S., López-Barroso, D., José Torres-Prioris, M., Croxson, P. L. \& Berthier, M. L. Plasticity in the Working Memory System: Life Span Changes and Response to Injury. Neuroscientist (2018). doi:10.1177/1073858417717210

70. Shoji, H., Takao, K., Hattori, S. \& Miyakawa, T. Age-related changes in behavior in C57BL/6J mice from young adulthood to middle age. Mol. Brain (2016). doi:10.1186/s13041-016-0191-9

71. Branch, S. Y., Sharma, R. \& Beckstead, M. J. Aging decreases L-type calcium channel currents and pacemaker firing fidelity in substantia nigra dopamine neurons. J. Neurosci. (2014). doi:10.1523/JNEUROSCI.4228-13.2014

72. Lecours, C. et al. Microglial implication in Parkinson's disease: Loss of beneficial physiological roles or gain of inflammatory functions? Frontiers in Cellular Neuroscience (2018). doi:10.3389/fncel.2018.00282

73. Newcombe, E. A. et al. Inflammation: the link between comorbidities, genetics, and Alzheimer's disease. J. Neuroinflammation (2018). doi:10.1186/s12974-018-1313-3

74. Boisvert, M. M., Erikson, G. A., Shokhirev, M. N. \& Allen, N. J. The Aging Astrocyte 
Transcriptome from Multiple Regions of the Mouse Brain. Cell Rep. (2018). doi:10.1016/j.celrep.2017.12.039

75. Orre, M. et al. Acute isolation and transcriptome characterization of cortical astrocytes and microglia from young and aged mice. Neurobiol. Aging (2014). doi:10.1016/j.neurobiolaging.2013.07.008

76. Kim, W. G. et al. Regional difference in susceptibility to lipopolysaccharide-induced neurotoxicity in the rat brain: Role of microglia. J. Neurosci. (2000). doi:10.1523/jneurosci.20-16-06309.2000

77. McCoy, M. K. et al. Blocking soluble tumor necrosis factor signaling with dominantnegative tumor necrosis factor inhibitor attenuates loss of dopaminergic neurons in models of Parkinson's disease. J. Neurosci. (2006). doi:10.1523/JNEUROSCI.1504-06.2006

78. Bellucci, A. et al. Parkinson's disease: From synaptic loss to connectome dysfunction. Neuropathology and Applied Neurobiology (2016). doi:10.1111/nan.12297

79. Bell, K. F. S. \& Hardingham, G. E. The influence of synaptic activity on neuronal health. Current Opinion in Neurobiology (2011). doi:10.1016/j.conb.2011.01.002

80. Morrison, J. H. \& Baxter, M. G. The ageing cortical synapse: Hallmarks and implications for cognitive decline. Nature Reviews Neuroscience (2012). doi:10.1038/nrn3200

81. Burke, S. N. \& Barnes, C. A. Neural plasticity in the ageing brain. Nature Reviews Neuroscience (2006). doi:10.1038/nrn1809

82. Walker, K. A. et al. Systemic inflammation during midlife and cognitive change over 20 years: The ARIC Study. Neurology (2019). doi:10.1212/WNL.0000000000007094

83. Heir, R. \& Stellwagen, D. TNF-Mediated Homeostatic Synaptic Plasticity: From in vitro to in vivo Models. Frontiers in Cellular Neuroscience (2020).

doi:10.3389/fncel.2020.565841

84. Prieto, G. A. \& Cotman, C. W. Cytokines and cytokine networks target neurons to modulate long-term potentiation. Cytokine and Growth Factor Reviews (2017). doi:10.1016/j.cytogfr.2017.03.005

85. Chowdhury, R. et al. Dopamine restores reward prediction errors in old age. Nat. Neurosci. (2013). doi:10.1038/nn.3364

86. Siddiqi, Z., Kemper, T. L. \& Killiany, R. Age-related neuronal loss from the substantia nigra-pars compacta and ventral tegmental area of the rhesus monkey. J. Neuropathol. Exp. Neurol. (1999). doi:10.1097/00005072-199909000-00006

87. Gagne, J. J. \& Power, M. C. Anti-inflammatory drugs and risk of Parkinson disease: A meta-analysis. Neurology (2010). doi:10.1212/WNL.0b013e3181d5a4a3

88. McGeer, P. L., Schulzer, M. \& McGeer, E. G. Arthritis and anti-inflammatory agents as possible protective factors for Alzheimer's disease: A review of 17 epidemiologic studies. Neurology (1996). doi:10.1212/WNL.47.2.425

89. Chen, H. et al. Nonsteroidal antiinflammatory drug use and the risk for Parkinson's disease. Ann. Neurol. (2005). doi:10.1002/ana.20682

90. Soto, C. \& Pritzkow, S. Protein misfolding, aggregation, and conformational strains in neurodegenerative diseases. Nature Neuroscience (2018). doi:10.1038/s41593-018-0235-9

91. Taetzsch, T. \& Block, M. L. Pesticides, Microglial NOX2, and Parkinson's Disease. J. Biochem. Mol. Toxicol. (2013). doi:10.1002/jbt.21464

92. Hanamsagar, R. \& Bilbo, S. D. Environment matters: microglia function and dysfunction in a changing world. Current Opinion in Neurobiology (2017).

doi:10.1016/j.conb.2017.10.007 
93. Wooten, G. F., Currie, L. J., Bovbjerg, V. E., Lee, J. K. \& Patrie, J. Are men at greater risk for Parkinson's disease than women? J. Neurol. Neurosurg. Psychiatry (2004). doi:10.1136/jnnp.2003.020982

94. Kopec, A. M., Smith, C. J., Ayre, N. R., Sweat, S. C. \& Bilbo, S. D. Microglial dopamine receptor elimination defines sex-specific nucleus accumbens development and social behavior in adolescent rats. Nat. Commun. 9, 3769 (2018).

95. VanRyzin, J. W. et al. Microglial Phagocytosis of Newborn Cells Is Induced by Endocannabinoids and Sculpts Sex Differences in Juvenile Rat Social Play. Neuron 102, 435-449 (2019).

96. Lenz, K. M., Nugent, B. M., Haliyur, R. \& McCarthy, M. M. Microglia Are Essential to Masculinization of Brain and Behavior. J. Neurosci. 33, 2761-72 (2013).

97. Fu, H., Hardy, J. \& Duff, K. E. Selective vulnerability in neurodegenerative diseases. Nature Neuroscience (2018). doi:10.1038/s41593-018-0221-2

98. Fendrick, S. E., Xue, Q. S. \& Streit, W. J. Formation of multinucleated giant cells and microglial degeneration in rats expressing a mutant $\mathrm{Cu} / \mathrm{Zn}$ superoxide dismutase gene. $J$. Neuroinflammation (2007). doi:10.1186/1742-2094-4-9

99. Naito, M. et al. Ultrastructural behavior of human immunodeficiency virus (HIV) in multinucleated giant cells in the brain of a japanese hemophiliac presenting AIDS encephalopathy. Ultrastruct. Pathol. (1989). doi:10.3109/01913128909048493

100. Hornik, T. C., Neniskyte, U. \& Brown, G. C. Inflammation induces multinucleation of Microglia via PKC inhibition of cytokinesis, generating highly phagocytic multinucleated giant cells. J. Neurochem. (2014). doi:10.1111/jnc.12477

\section{FIGURE LEGENDS}

Figure 1. VTA microglia show early increases in cell density. A - Representative images of microglia in the NAc and VTA of 2 month (mo), 18 mo, and 22-24 mo old CX3CR1 $1^{E G F P /+}$ mice. Images are maximum projections of stacks of confocal images. B - Quantification of NAc and VTA microglial density during aging; VTA microglia show early and significant increases in cell density. Each data point represents the average microglial density value obtained for one mouse. Two-way ANOVA: main effect of age $\mathrm{F}(2,43)=7.4, \mathrm{P}=0.002$; main effect of brain region $\mathrm{F}(1,43)=21.0, \mathrm{P}<0.0001$; interaction $\mathrm{F}(2,43)=5.6, \mathrm{P}<0.007 . * \mathrm{P}=0.0218$ mo VTA vs. 2 mo VTA. ** $\mathrm{P}<0.000122-24$ mo VTA vs. 2 mo VTA. $\mathrm{N}=4-9$ mice analyzed per age, with 3 images analyzed per brain region per mouse. $\mathbf{C}-$ Comparison of NAc and VTA microglial density within individual mice at different ages. Data points from the same mouse are colored alike. At 2 mo of age, VTA microglial density is consistently less than NAc microglial density (* $\mathrm{P}=0.0002$, two tailed paired t-test). At 18mo of age, the relationship between NAc and VTA microglial density is no longer consistent or significant $(P=0.06$, two tailed paired t-test $)$ and it remains inconsistent and non-significant at 22-24 mo of age ( $\mathrm{P}=0.2$, two tailed paired t-test). 
Figure 2. Increases in microglial density during aging arise from proliferation of resident microglia. A - Examples of microglia exhibiting morphological profiles of cell division. Yellow arrows highlight closely approximated or interconnected microglial cell somas with distinct DAPI+ nuclei. B - Microglia that exhibit morphological profiles of cell division are labeled by BrdU following 2-week treatment of aging mice with BrdU. Yellow arrows highlight lipofuscin autofluorescence that is evident in red wavelengths and can clearly be distinguished from BrdU labeling of the cell nucleus. $\mathbf{C}$ - Representative images from the VTA of $2 \mathrm{mo}$ and 20-24mo $C X 3 C R 1^{\text {CreER-IRES-EYFP }}$;iDTR mice that were treated with tamoxifen at $2 \mathrm{mo}$ of age to label resident microglia present in the CNS at young adult ages. Examples of Iba1+DTR+ microglia (yellow boxes) and Iba1+DTR- microglia (cyan boxes) are shown at higher magnification in $\mathbf{D}$. $\mathbf{E}$ - Quantification of the \% of Iba1+ microglia that are also DTR+; this percentage remains consistent across age groups in both the VTA and NAc (Two-way ANOVA: main effect of age $\mathrm{F}(1,25)=2.9, \mathrm{P}=0.1$ n.s.; main effect of brain region $\mathrm{F}(1,25)=0.16, \mathrm{P}=0.69$ n.s.; interaction $\mathrm{F}(1,25)=1.2, \mathrm{P}=0.28$ n.s. $) . \mathbf{F}-$ Iba1+DTR + microglia increase their density at similar rates to density increases in the overall microglial population as shown by normalizing 20-24mo microglial densities to values observed at 2mo. (Two-way ANOVA: main effect of region $\mathrm{F}(1,25)=2.7, \mathrm{P}=0.11$ n.s.; main effect of cell population $\mathrm{F}(1,25)=3.6, \mathrm{P}=0.07$ n.s.; interaction $\mathrm{F}(1,25)=0.89, \mathrm{P}=0.35$ n.s.). $\mathrm{N}=5-9$ mice analyzed per age, with 3 images analyzed per brain region per mouse.

Figure 3. Microglial tissue coverage increases during aging. A - Representative high magnification images of microglial branching structure in the NAc and VTA of 2mo and 18mo old CX3CR1 ${ }^{E G F P /+}$ mice. Distal processes highlighted by red boxes shown at higher magnification in panels at right. Yellow arrow highlights an example of somatic swellings observed in some microglia at $18 \mathrm{mo}$. B - Quantification of the percent coverage of the field of view (FOV) by microglial somas and processes. Two-way ANOVA: main effect of age $\mathrm{F}(1,19)=$ 23.4, $\mathrm{P}=0.0002$; main effect of brain region $\mathrm{F}(1,19)=338.6, \mathrm{P}<0.0001$; interaction $\mathrm{F}(1,19)=$ $0.004, \mathrm{P}=0.95$ n.s. $* \mathrm{P}=0.0218 \mathrm{mo}$ VTA vs. 2 mo VTA, 18 mo NAc vs. 2 mo NAc. $\mathrm{N}=4-6$ mice analyzed per age, with 3 images analyzed per brain region per mouse. $\mathbf{C}-$ Estimated tissue coverage of individual microglial cells calculated by dividing the total microglial coverage in a field of view by the number of microglial cells present in that field of view. D - High magnification examples of somatic swellings (yellows arrows) from microglia in the VTA and NAc of 18mo mice together with staining for DAPI and CD68 indicating that these swellings contain lysosomes and do not represent instances of cell division.

Figure 4. Local increases in microglial density are associated with “pockets” of inflammation. A - Cartoon indicating regions microdissected for mRNA and protein-level analysis in the prefrontal cortex (PFC), nucleus accumbens (NAc) and ventral tegmental area (VTA). PFC and NAc were microdissected from acute coronal brain sections and VTA from horizontal midbrain sections. B - Relative expression of tumor necrosis factor alpha (TNF $\alpha$, left) and interleukin 1 beta (IL-1 $\beta$, right) mRNA in the PFC, NAc, and VTA at 2, 18, and 24 months (mo). TNF $\alpha$ 2-way ANOVA: main effect of age $\mathrm{F}(2,54)=14.1, \mathrm{P}<0.0001$; main effect of brain region $\mathrm{F}(2,54)=6.9, \mathrm{P}=0.002$; interaction $\mathrm{F}(4,54)=4.0, \mathrm{P}=0.007 . \mathbf{I L}-1 \boldsymbol{\beta}$ 2-way ANOVA: main effect of age $\mathrm{F}(2,56)=8.4, \mathrm{P}=0.0007$; main effect of brain region $\mathrm{F}(2,56)=5.2, \mathrm{P}=$ 0.009; interaction $\mathrm{F}(4,56)=3.3, \mathrm{P}=0.02$. ${ }^{*} \mathrm{P}<0.03 . \mathrm{N}=5-8$ mice analyzed per age, per brain region. $\mathbf{C}-$ Comparison of TNF $\alpha$ and IL-1 $\beta$ transcript across brain regions in individual mice. 
For a given age, data points from the same mouse are colored alike. Significant paired T-tests: * $\mathrm{P}<0.02$, PFC vs. NAc and PFC vs. VTA; \# $\mathrm{P}<0.02$ PFC vs. NAc and PFC vs. VTA; $\$ \mathrm{P}<$ 0.008 , VTA vs. NAc and VTA vs. PFC; $\&$ P $<0.02$, VTA vs. NAc and VTA vs. PFC. D - Local protein levels of TNF $\alpha$ (left), IL-1 $\beta$ (middle), and CXCL1 (right) as measured by highsensitivity ELISA. TNF $\alpha$ 2-way ANOVA: main effect of age $\mathrm{F}(2,53)=8.8, \mathrm{P}=0.0005$; main effect of brain region $\mathrm{F}(1,53)=126.9, \mathrm{P}<0.0001$; interaction $\mathrm{F}(2,53)=5.0, \mathrm{P}=0.01$. IL-1 $\mathbf{\beta}$ 2way ANOVA: main effect of age $\mathrm{F}(2,54)=3.0, \mathrm{P}=0.06$ n.s.; main effect of brain region $\mathrm{F}(1,54)$ $=95.1, \mathrm{P}<0.0001$; interaction $\mathrm{F}(2,54)=0.2, \mathrm{P}=0.8$ n.s. CXCL1: main effect of age $\mathrm{F}(2,54)=$ $0.6, \mathrm{P}=0.56$ n.s.; main effect of brain region $\mathrm{F}(1,54)=1.5, \mathrm{P}=0.23$ n.s.; interaction $\mathrm{F}(2,54)=$ $0.6, \mathrm{P}=0.0 .57$ n.s. $* \mathrm{P}<0.0001$ VTA vs. NAc. \# $\mathrm{P}<0.02$ VTA $24 \mathrm{mo}$ vs VTA $18 \mathrm{mo}$ and VTA24mo vs VTA 2mo. $\mathrm{N}=7-13$ mice analyzed per age, per brain region

Figure 5. Local increases in VTA microglial density and inflammation begin as early as middle age. A - Quantification of microglial cell density in the NAc and VTA of 2 and 13 mo old CX3CR1 ${ }^{E G F P /+}$ mice. Two-way ANOVA: main effect of age $\mathrm{F}(1,19)=1.6, \mathrm{P}=0.22$ n.s.; main effect of brain region $\mathrm{F}(1,19)=77.7, \mathrm{P}<0.0001$; interaction $\mathrm{F}(1,19)=13.2, \mathrm{P}=0.002 . * \mathrm{P}$ $=0.01$. $\mathrm{N}=4-6$ mice analyzed per age, with 3 images analyzed per brain region per mouse. $\mathbf{B}-$ Relative changes in microglial density in the NAc and VTA during aging. Microglial densities are normalized to values observed in 2mo animals. Two-way ANOVA: main effect of age $\mathrm{F}(3,53)=7.9, \mathrm{P}=0.0002$; main effect of brain region $\mathrm{F}(1,53)=44.5, \mathrm{P}<0.0001$; interaction $\mathrm{F}(3,53)=5.7, \mathrm{P}=0.002 .{ }^{*} \mathrm{P}<0.0005,18 \mathrm{mo}$ VTA vs. 18mo NAc and 22-24mo VTA vs. 2224mo NAc. C - Workflow schematic; midbrain (MB), striatum (STR), and cortex (CTX) were dissected from acute coronal forebrain sections followed by FACS isolation of EGFP+ microglia, RNA extraction, and ddPCR analysis of gene expression. D - Expression levels of TNF $\alpha$ transcript in microglia. Two-way ANOVA: main effect of age $\mathrm{F}(1,17)=6.1, \mathrm{P}=0.03$; main effect of brain region $\mathrm{F}(2,17)=7.5, \mathrm{P}=0.008$; interaction $\mathrm{F}(2,17)=1.6, \mathrm{P}=0.24$ n.s. * $\mathrm{P}<$ $0.03 \mathrm{MB}$ vs. Ctx and MB vs. STR. E - Comparison of NAc and VTA microglial TNF $\alpha$ expression within individual mice at 2 and 14 mo. Data points from the same mouse are colored alike. At 2 mo of age, no consistent relationship is observed in microglial expression of TNF $\alpha$ transcript across regions. At $14 \mathrm{mo}$ of age, MB microglia express higher levels of TNF $\alpha$ transcript than Ctx and STR microglia in the same mouse $(* \mathrm{P}<0.05$, one tailed paired t-test).

Figure 6. SNc microglia resemble VTA microglia during aging but more frequently form microglial clusters. A - Quantification of microglial density in the SNc in 2, 18, and 22-24mo old CX3CR1 ${ }^{E G F P /+}$ mice. One-way ANOVA F(2,15) $=9.9, \mathrm{P}=0.002$. ${ }^{*} \mathrm{P}<0.003,18 \mathrm{mo}$ SNc vs. 2mo SNc. \# $\mathrm{P}=0.02$ 22-24mo SNc vs. 2mo SNc. B - comparison of microglial density increases across aging in the VTA and SNc. Densities are normalized to values in each region at $2 \mathrm{mo}$ of age. Two-way ANOVA: main effect of age $\mathrm{F}(2,38)=19.1, \mathrm{P}<0.0001$; main effect of brain region $\mathrm{F}(1,38)=0.001, \mathrm{P}=0.97$ n.s.; interaction $\mathrm{F}(2,38)=0.7, \mathrm{P}=0.49 . \mathbf{C}-$ Quantification of the percent coverage of the field of view (FOV) by microglial somas and processes. $* \mathrm{P}=0.005$, two sample t-test. D - High magnification examples of somatic swellings (top panels) and process swellings (bottom panels) from SNc microglia in $18 \mathrm{mo} C X 3 C R 1^{\text {EGFP/+ }}$ mice. Yellow arrows and co-staining with DAPI and CD68 indicate that these swellings contain lysosomes and do not represent instances of cell division or engulfment of dying cells with pyknotic nuclei. $\mathbf{E}-$ Two examples of microglial cell clusters observed in the SNc of $18 \mathrm{mo}$ old CX3CR $1^{\text {EGFP /+ }}$ mice. F - Co-staining of the cluster at right in $E$ with DAPI and CD68, revealing that the cluster does 
not appear to contain engulfed pyknotic nuclei and that the cluster may only be composed of 2 microglia, despite appearing to contain more. CD68 staining is abundant within the cluster, but appeared more punctate than the large 3-4 $\mu \mathrm{m}$ CD68+ lysosomes observed in somatic and cell process swellings shown in $D$. G - Rough quantification of the frequency of microglial morphological abnormalities across the NAc, VTA, and SNc of $18 \mathrm{mo}$ old CX3CR1 $1^{E G F /+}$ mice. Somatic swellings one-way ANOVA $\mathrm{F}(2,11)=0.5, \mathrm{P}=0.6$ n.s. Cell process swellings one-way ANOVA $F(2,11)=0.3, P=0.7$ n.s. Microglial clusters one-way $\operatorname{ANOVA~} F(2,11)=2.5, P=0.14$ n.s.

Figure 7. VTA and SNc microglial responses to aging are not accompanied by significant neuronal loss reactive changes in astrocyte population. A - Representative images of astrocytes in the NAc and VTA of 2 month (mo) and 24mo old ALDH1L1-EGFP mice. Images are maximum projections of stacks of confocal images. Dashed yellow line shows the boundary of the VTA. B - Quantification of NAc and VTA astrocyte density during aging. Each data point represents the average astrocyte density value obtained for one mouse. Two-way ANOVA: main effect of age $\mathrm{F}(1,11)=3.2, \mathrm{P}=0.11$ n.s.; main effect of brain region $\mathrm{F}(1,11)=8.1, \mathrm{P}=0.02$; interaction $\mathrm{F}(1,11)=1.3, \mathrm{P}=0.29$ n.s. $\$ \mathrm{P}=0.02$ NAc vs. VTA. $\mathbf{C}-$ Representative confocal image of TH immunostaining from a 2 mo $C X 3 C R 1^{E G F P /+}$ mouse showing the divisions between VTA and SNc. Panels at right show higher magnification images of TH+ neurons in the VTA and SNc and lower panels show staining for both TH, which marks dopamine neurons, and NeuN which labels all neurons. D - TH and NeuN immunostaining for a representative 24 mo $C X 3 C R 1^{E G F P /+}$ mouse. Greater background autofluorescence (lipofuscin) is visible in this tissue but does not interfere with clear TH and NeuN labeling of resident neurons. E - Quantification of total number of $\mathrm{TH}+$ neurons and $\mathrm{TH}$-negative (non-TH) neurons across 3 stereologically matched brain sections during aging in the VTA and SNc. TH+ neuron sum Two-way ANOVA: main effect of age $\mathrm{F}(2,17)=43, \mathrm{P}=0.66$ n.s.; main effect of brain region $\mathrm{F}(1,17)=$ $0.01, \mathrm{P}=0.92$ n.s.; interaction $\mathrm{F}(2,17)=0.24$, $\mathrm{P}=0.79$ n.s. Non-TH neuron sum Two-way ANOVA: main effect of age $\mathrm{F}(2,17)=1.31, \mathrm{P}=0.30$; main effect of brain region $\mathrm{F}(1,17)=5.4$, $\mathrm{P}=0.04$; interaction $\mathrm{F}(2,17)=0.04, \mathrm{P}=0.96$ n.s. $\$ \mathrm{P}=0.04$ VTA vs. SNc. $\mathbf{F}-$ Quantification of density of TH+ neurons and TH-negative (non-TH) neurons during aging in the VTA and SNc. TH+ neuron density Two-way ANOVA: main effect of age $\mathrm{F}(2,17)=6.8, \mathrm{P}=0.01$; main effect of brain region $\mathrm{F}(1,17)=0.51, \mathrm{P}=0.49$ n.s.; interaction $\mathrm{F}(2,17)=0.49, \mathrm{P}=0.63$ n.s. $* \mathrm{P}<0.03$, $2 \mathrm{mo}$ vs. $18 \mathrm{mo}$ and $2 \mathrm{mo}$ vs. $22-24 \mathrm{mo}$. Non-TH neuron density Two-way ANOVA: main effect of age $\mathrm{F}(2,17)=8.97, \mathrm{P}=0.004$; main effect of brain region $\mathrm{F}(1,17)=29.64, \mathrm{P}=0.0002$; interaction $\mathrm{F}(2,17)=0.04, \mathrm{P}=0.96$ n.s. $\# \mathrm{P}<0.05$, $2 \mathrm{mo}$ vs. $18 \mathrm{mo}$ and $2 \mathrm{mo}$ vs. $22-24 \mathrm{mo} . \$ \mathrm{P}=$ 0.0002 VTA vs. SNc.

Figure 8. Region-specific microglial responses to aging are modulated by CX3CR1signaling axis and microglial ablation/repopulation. A - Representative confocal images of microglia in the VTA of young and aging wildtype mice as revealed by immunostaining for microglial marker Iba1. B - Representative confocal images of microglia in the VTA of young and aging CX3CR1 ${ }^{\text {EFF /EGFP }}$ (CX3CR1-KO) mice. $\mathbf{C}$ - Quantification of microglial density in the NAc and VTA of young and aging wildtype mice. Two-way ANOVA: main effect of age $\mathrm{F}(1,18)=1.72, \mathrm{P}=0.21$ n.s.; main effect of brain region $\mathrm{F}(1,18)=37.9, \mathrm{P}<0.0001$; interaction $\mathrm{F}(2,18)=5.6, \mathrm{P}=0.03 . \mathbf{D}-$ Quantification of microglial density in the NAc and VTA of young and aging CX3CR1-KO mice. Two-way ANOVA: main effect of age $\mathrm{F}(1,18)=68.6, \mathrm{P}<0.0001$; 
main effect of brain region $\mathrm{F}(1,18)=23.9, \mathrm{P}=0.0002$; interaction $\mathrm{F}(2,18)=9.7, \mathrm{P}=0.006$. * $\mathrm{P}=$ 0.0002 , VTA 2 mo vs. VTA 18 mo. E - Microglial density when normalized to 2 mo values from each brain region and genotype. Two-way ANOVA: main effect of genotype $F(1,16)=$ $18.9, \mathrm{P}=0.0005$; main effect of brain region $\mathrm{F}(1,16)=63.4, \mathrm{P}<0.0001$; interaction $\mathrm{F}(2,16)=$ 2.6, $\mathrm{P}=0.12$ n.s. * $\mathrm{P}=0.004$, VTA Wt vs. VTA KO. F - Representative confocal images of VTA microglia in 13-20 mo CX3CR1 $1^{\text {EGF/+ }}$ mice treated with control (CTR) or Plexxikon 5622 CSFR1 inhibitor diet $(P L X)$ as well as mice treated with PLX followed by control diet for 21 days to allow for microglial repopulation (Repop). G - Quantification of microglial density in CTR, PLX, and Repop mice in the NAc. One-way ANOVA: $\mathrm{F}(2,14)=125.4, \mathrm{P}<0.0001$. * $\mathrm{P}<$ 0.0001, CTR vs. PLX and Repop vs PLX. H - Quantification of microglial density in CTR, PLX, and Repop mice in the VTA. One-way ANOVA: $\mathrm{F}(2,14)=105.9, \mathrm{P}<0.0001 .{ }^{*} \mathrm{P}<$ 0.0001 , CTR vs. PLX and Repop vs PLX. \# P = 0.004, CTR vs. Repop. I - Microglial density when normalized to 2 mo values from each brain region and treatment. Two-way ANOVA: main effect of treatment $\mathrm{F}(1,19)=10.5, \mathrm{P}=0.005$; main effect of brain region $\mathrm{F}(1,19)=6.17, \mathrm{P}=$ 0.02 ; interaction $\mathrm{F}(2,19)=5.5, \mathrm{P}=0.03 . * \mathrm{P}<0.007$, VTA CTR vs. VTA repop. 


\section{Figure 1}

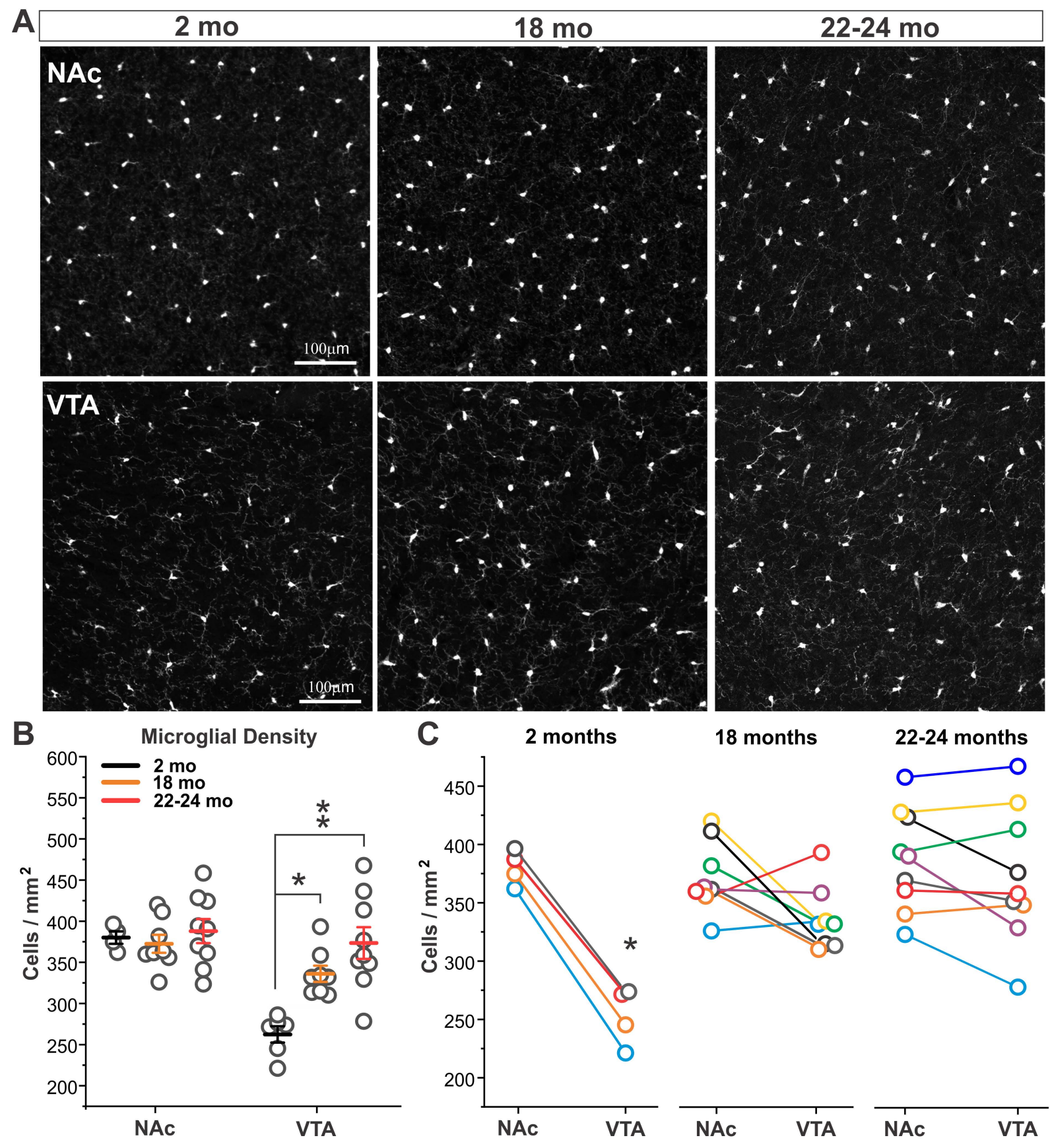


Figure 2.
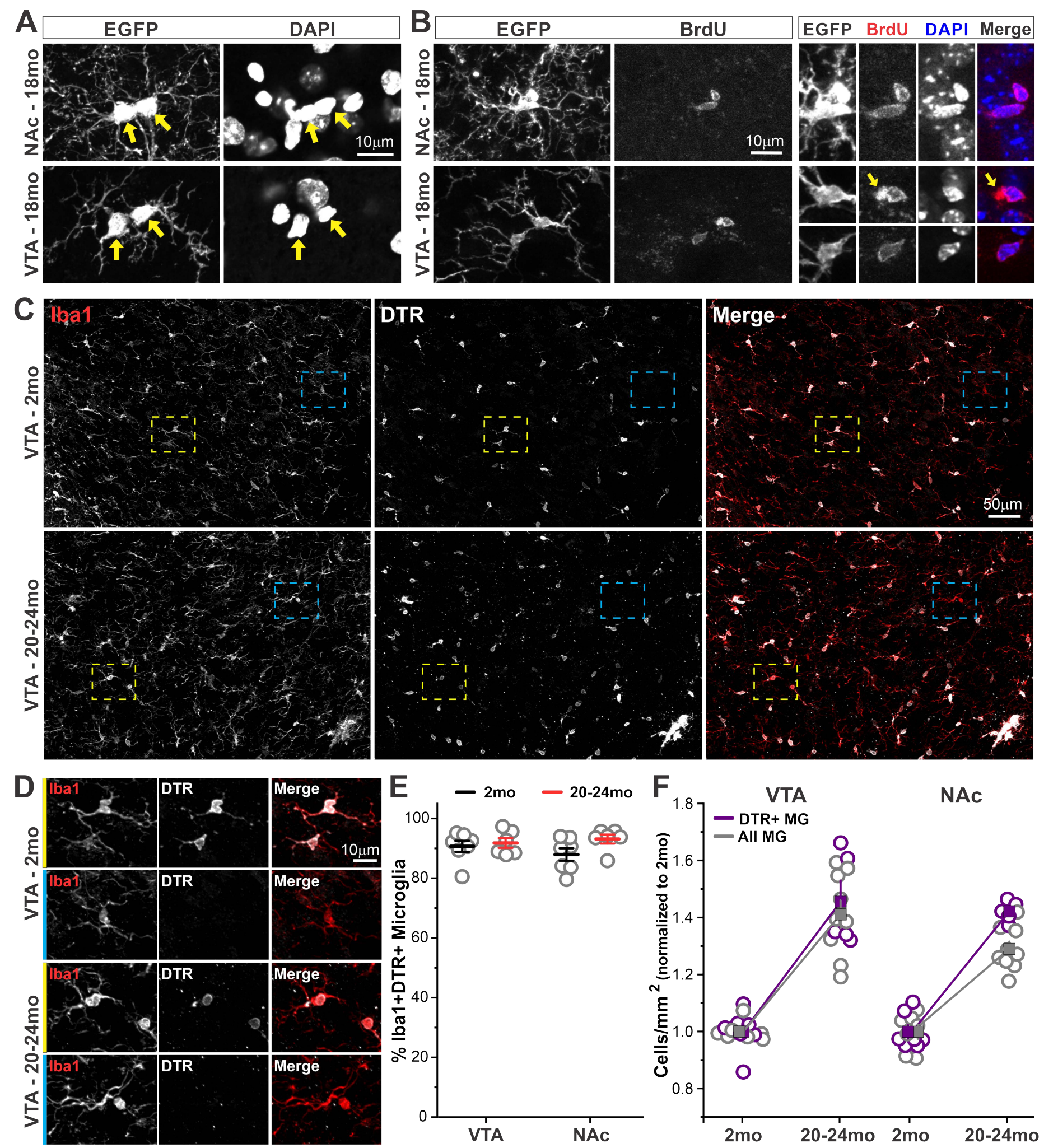


\section{Figure 3}
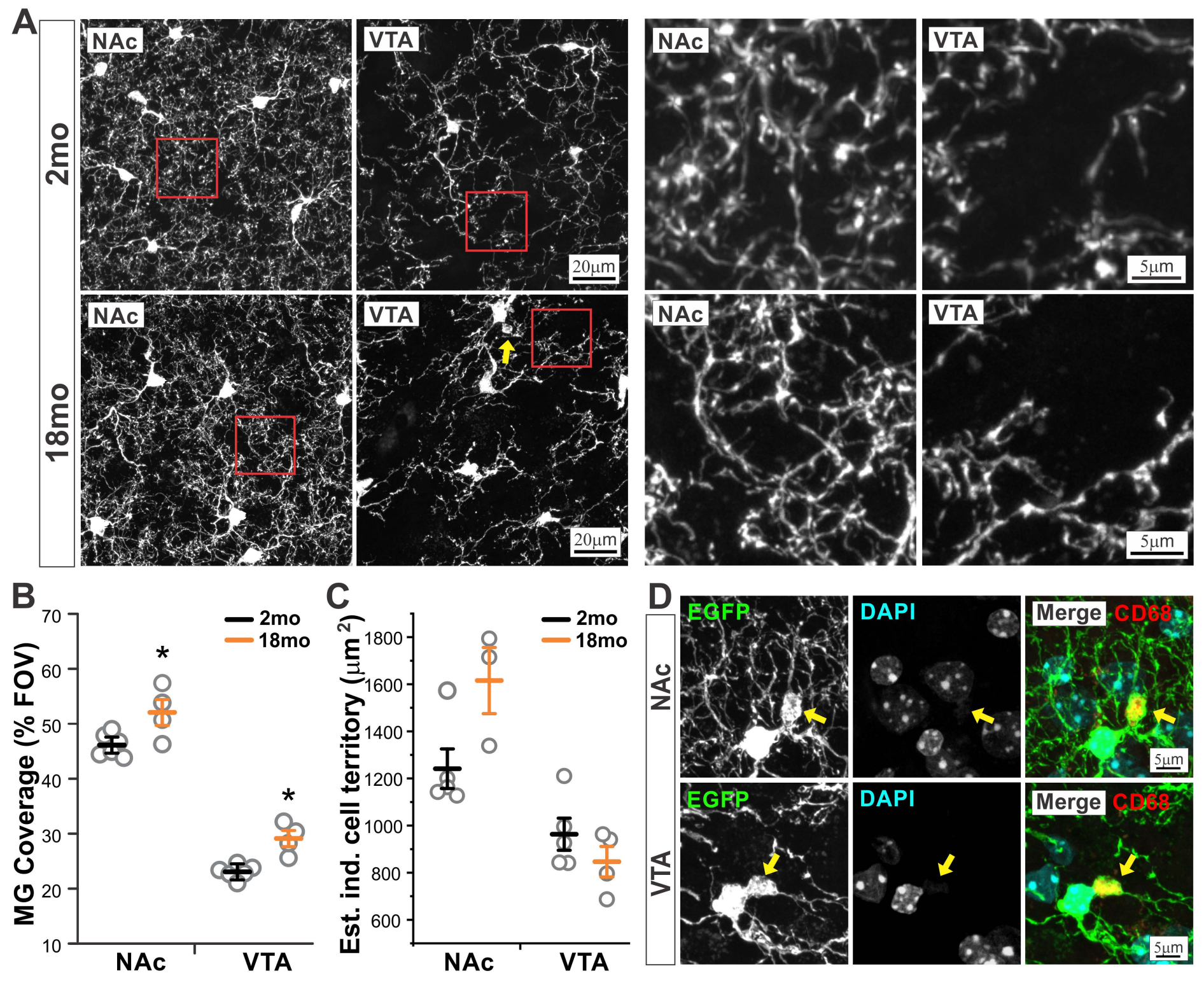

C

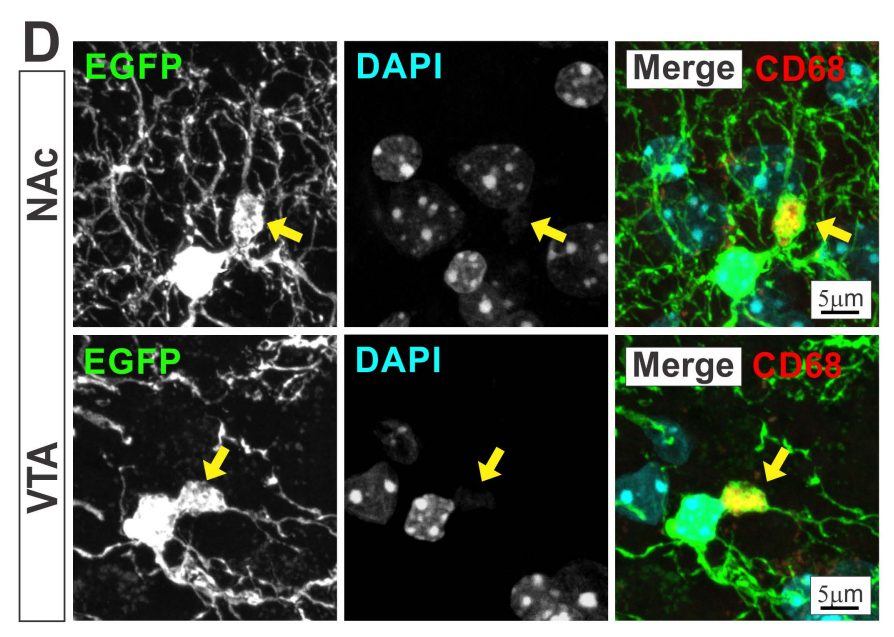




\section{Figure 4.}
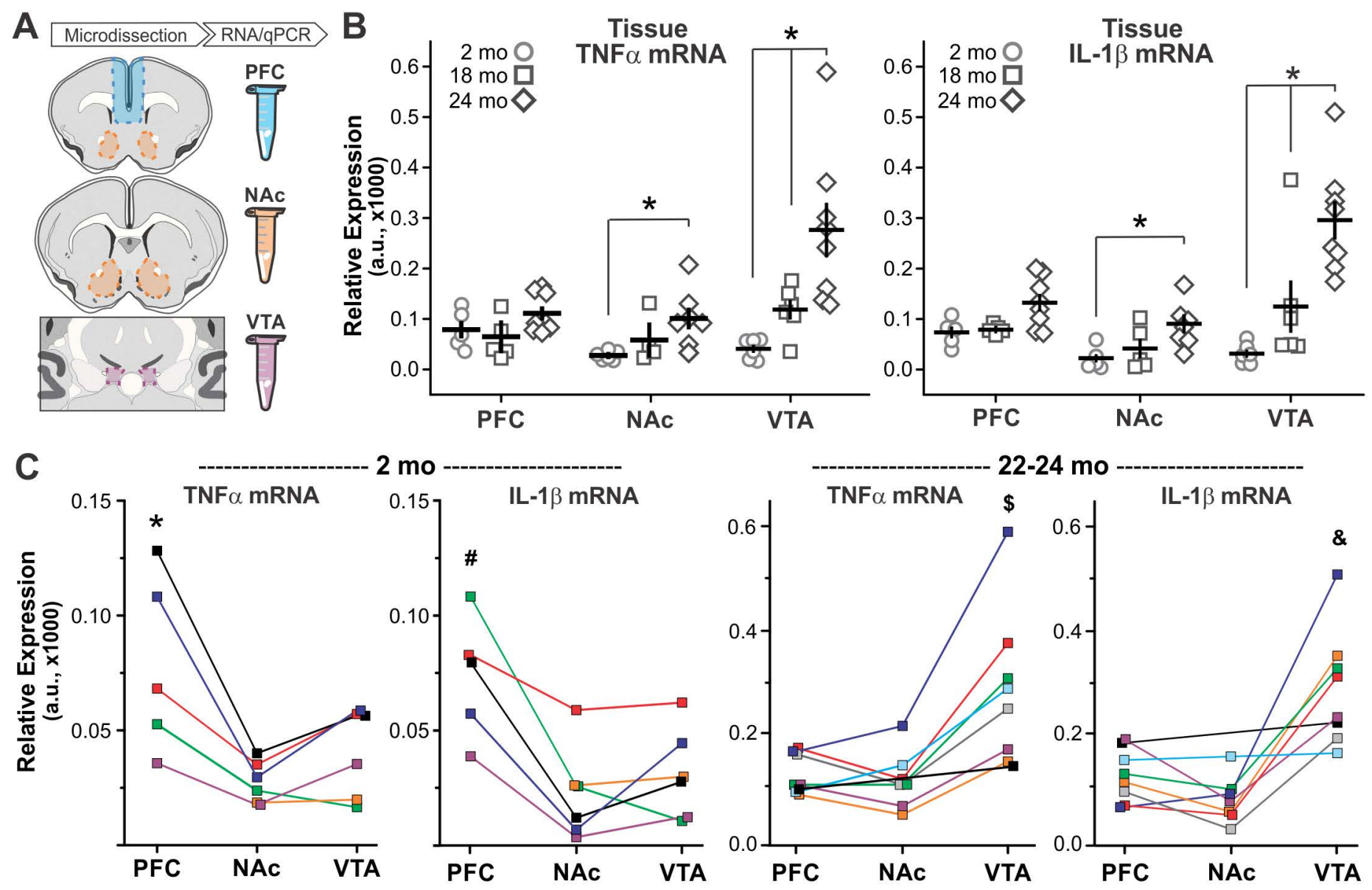

22-24 mo
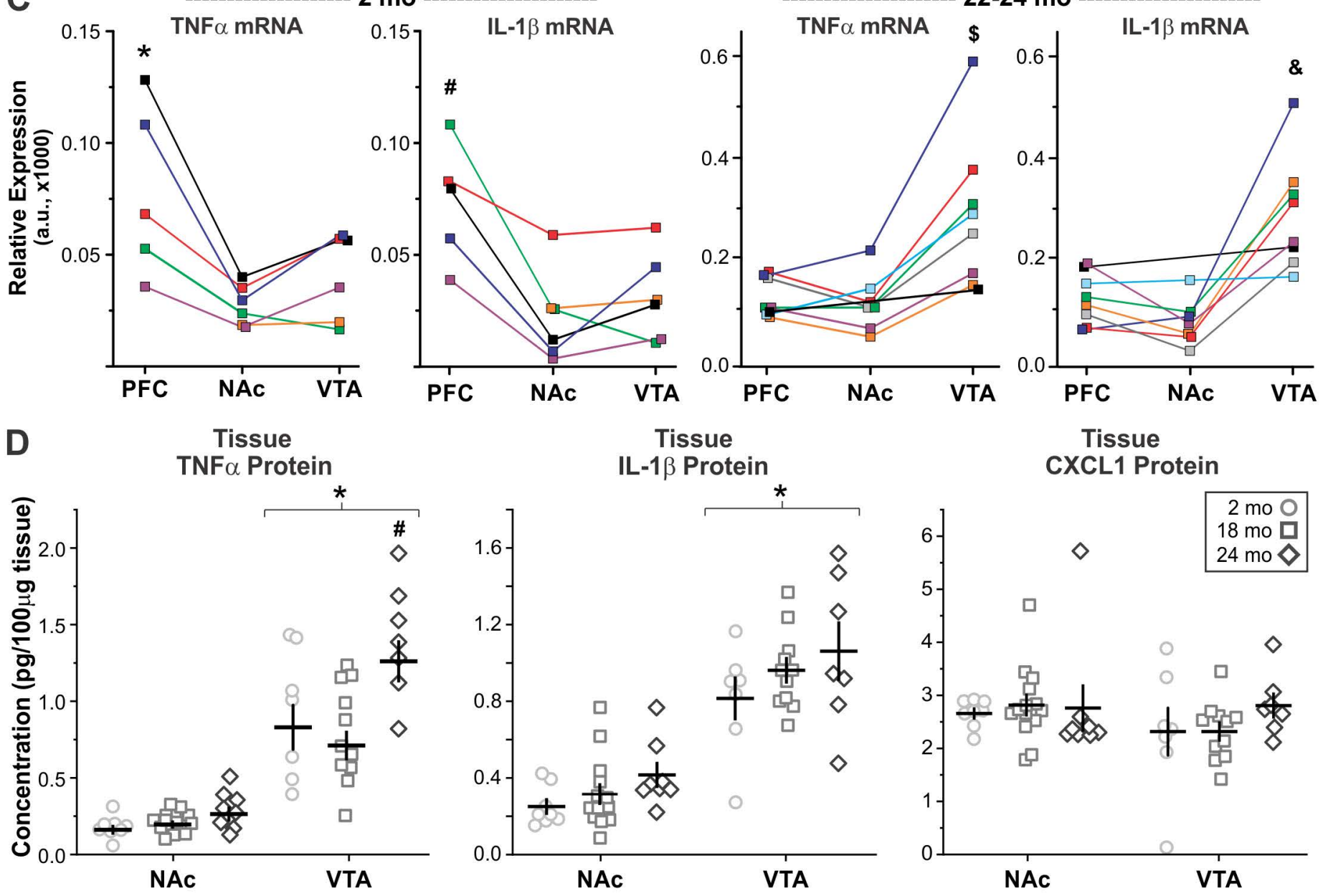

Tissue

IL-1 $\beta$ Protein
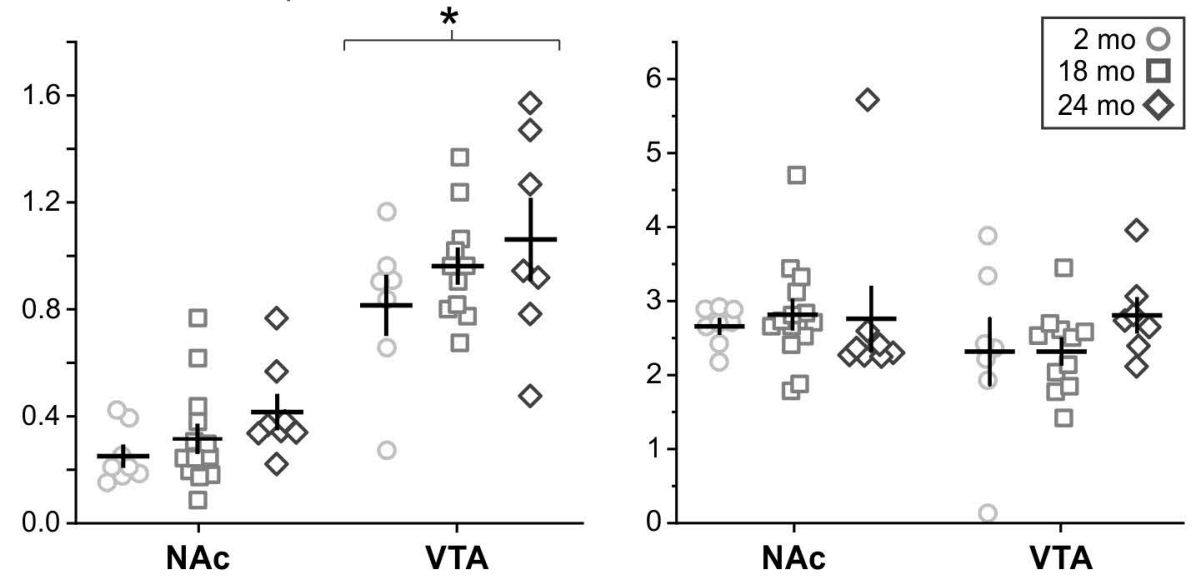


\section{Figure 5.}
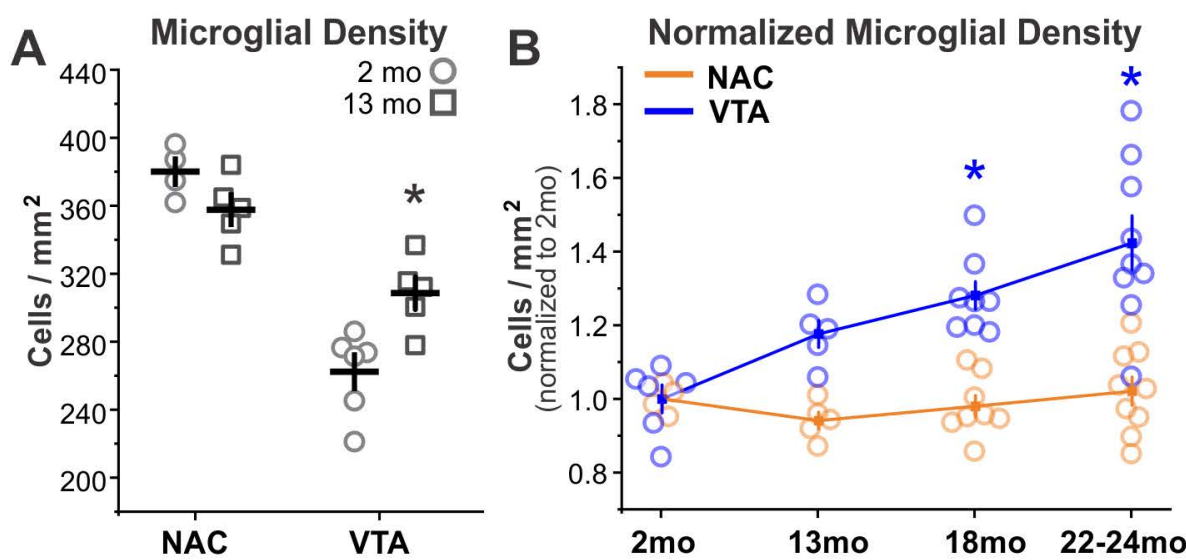

C

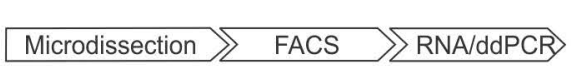

D Microglial TNF $\alpha$ mRNA
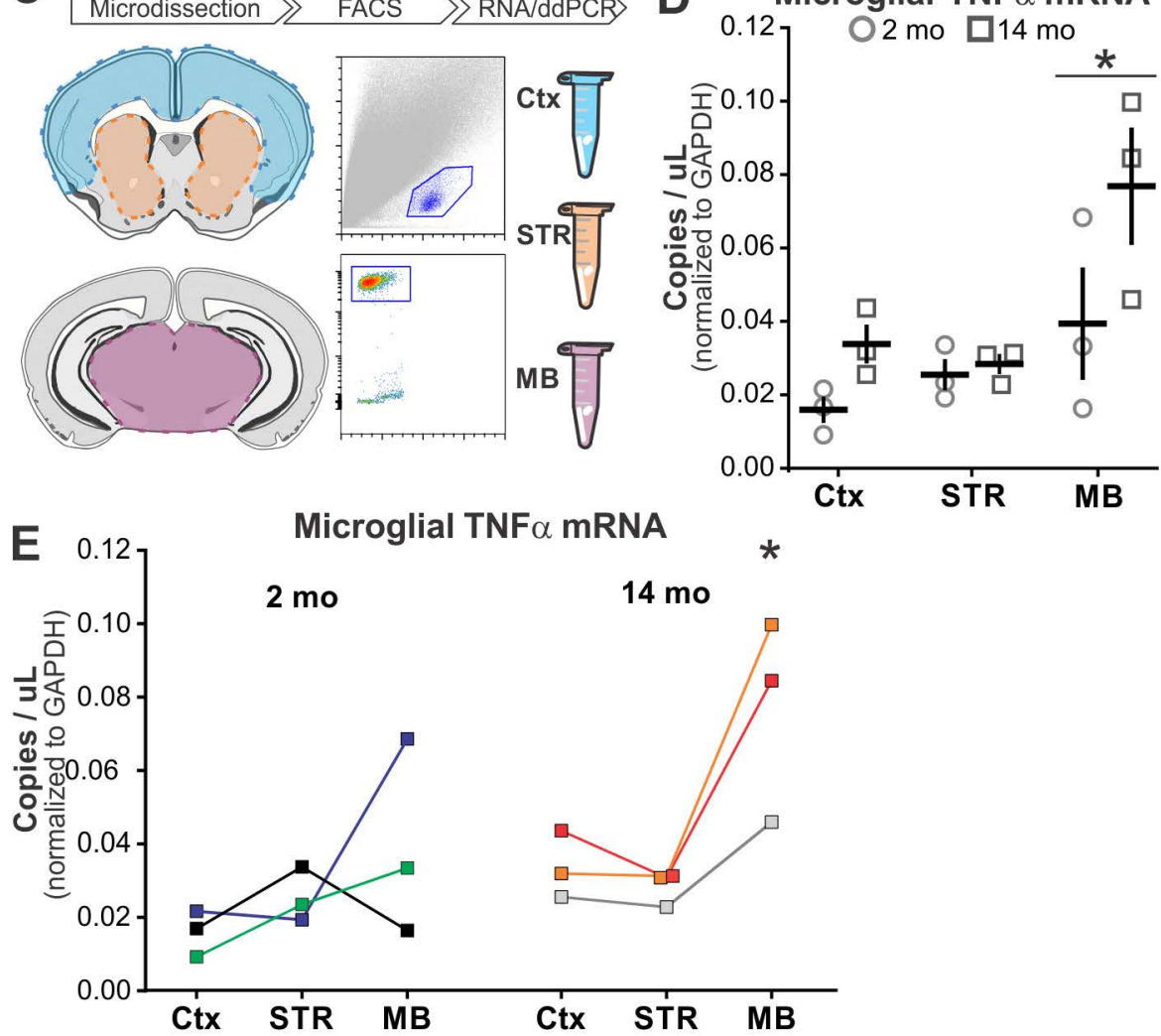


\section{Figure 6.}
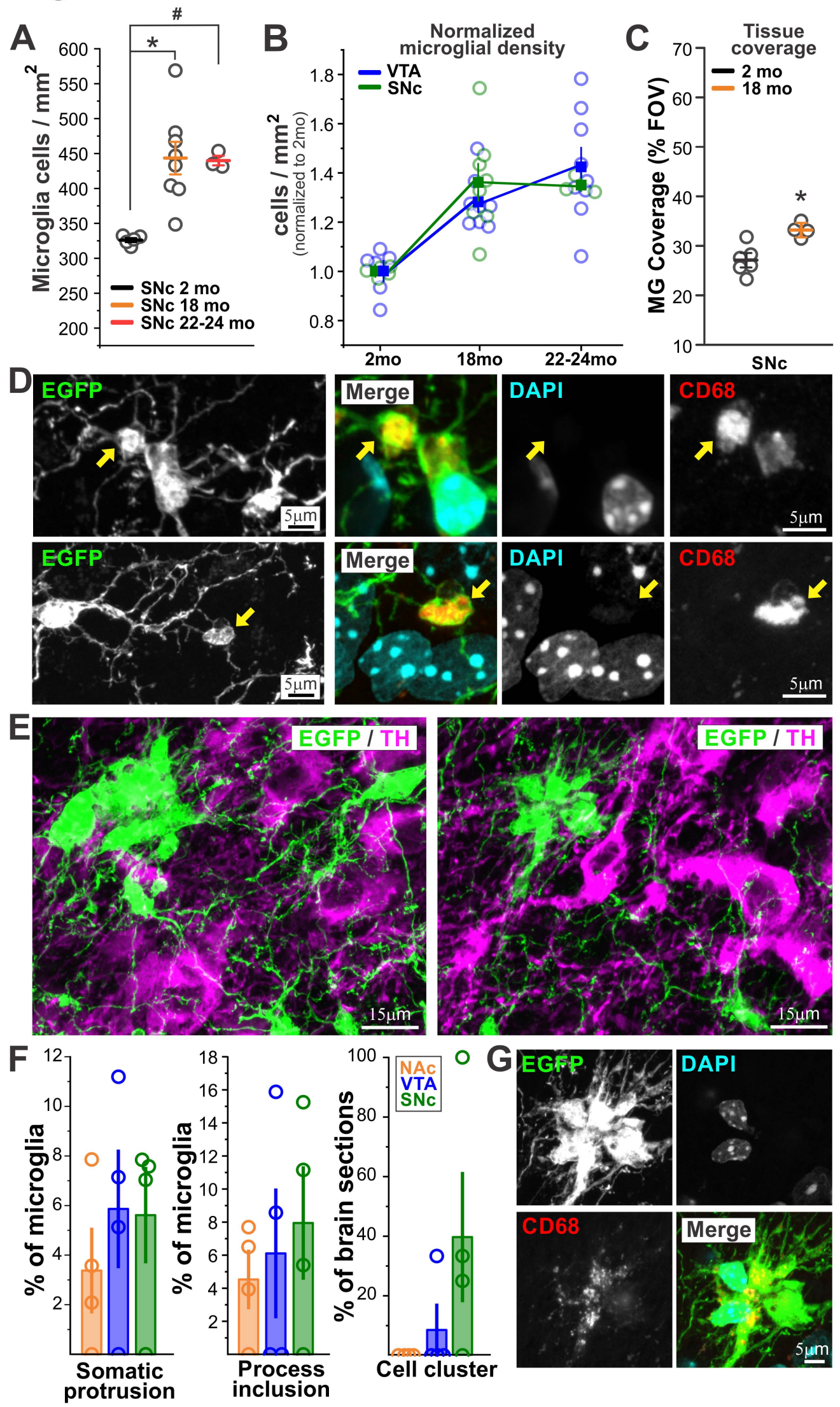


\section{Figure 7.}
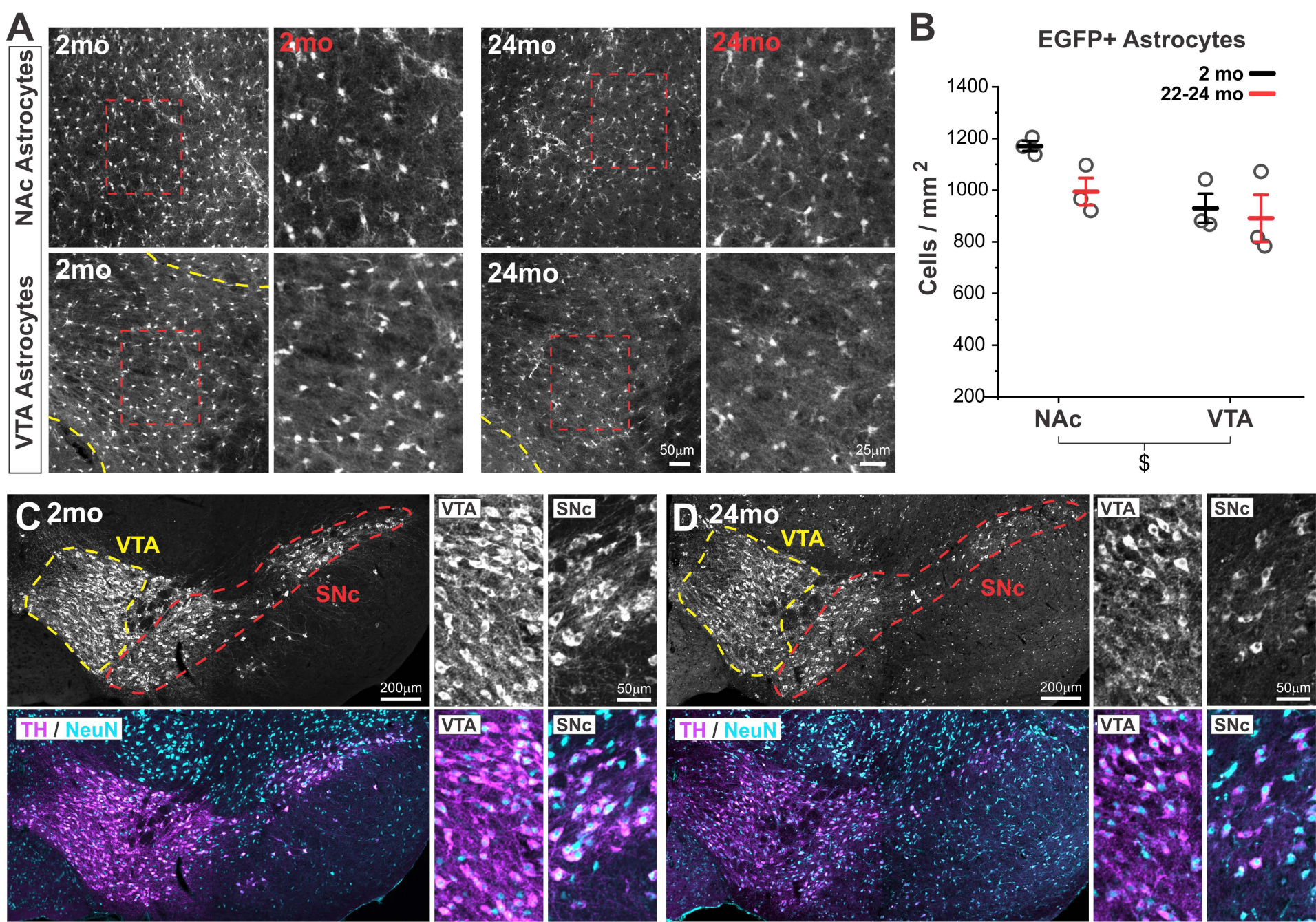

\section{E $\mathrm{NeuN}+\mathrm{TH}+$ neurons}

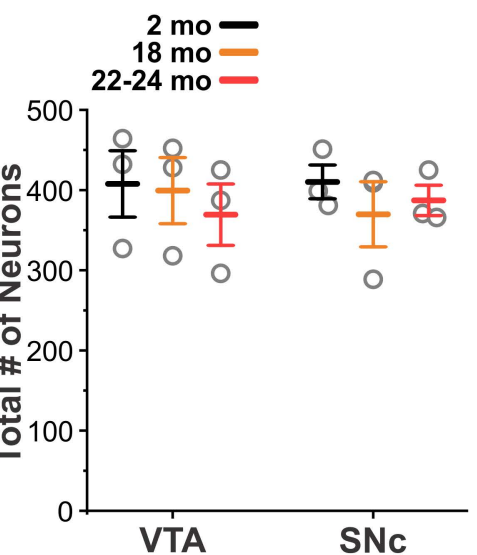

NeuN+TH- neurons
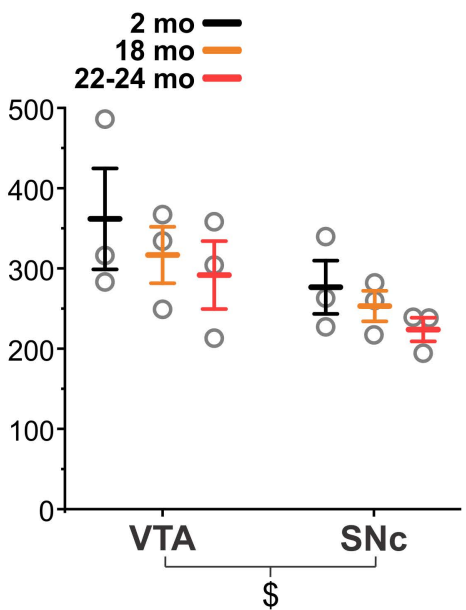
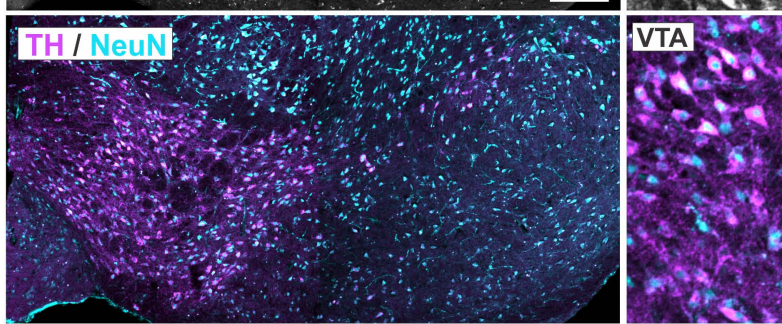

F

$\mathrm{NeuN}+\mathrm{TH}+$ neurons

$2 \mathrm{mo}$
$18 \mathrm{mo}$

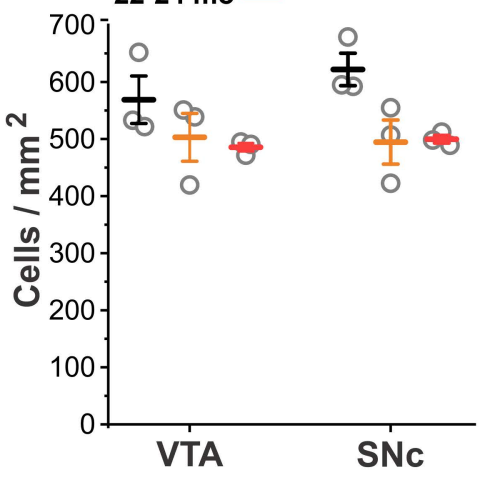

NeuN+TH- neurons

$28 \mathrm{mo}-\square \#$

22-24 $\mathrm{mo}-$

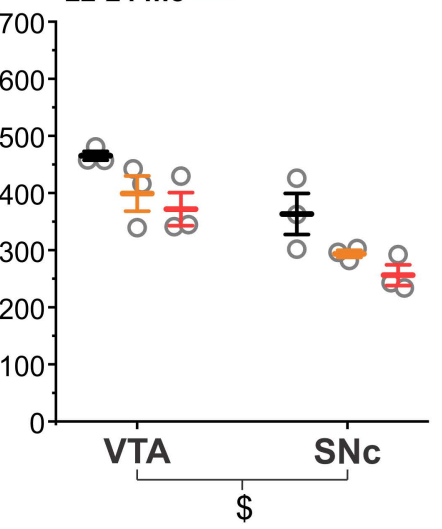




\section{Figure 8.}
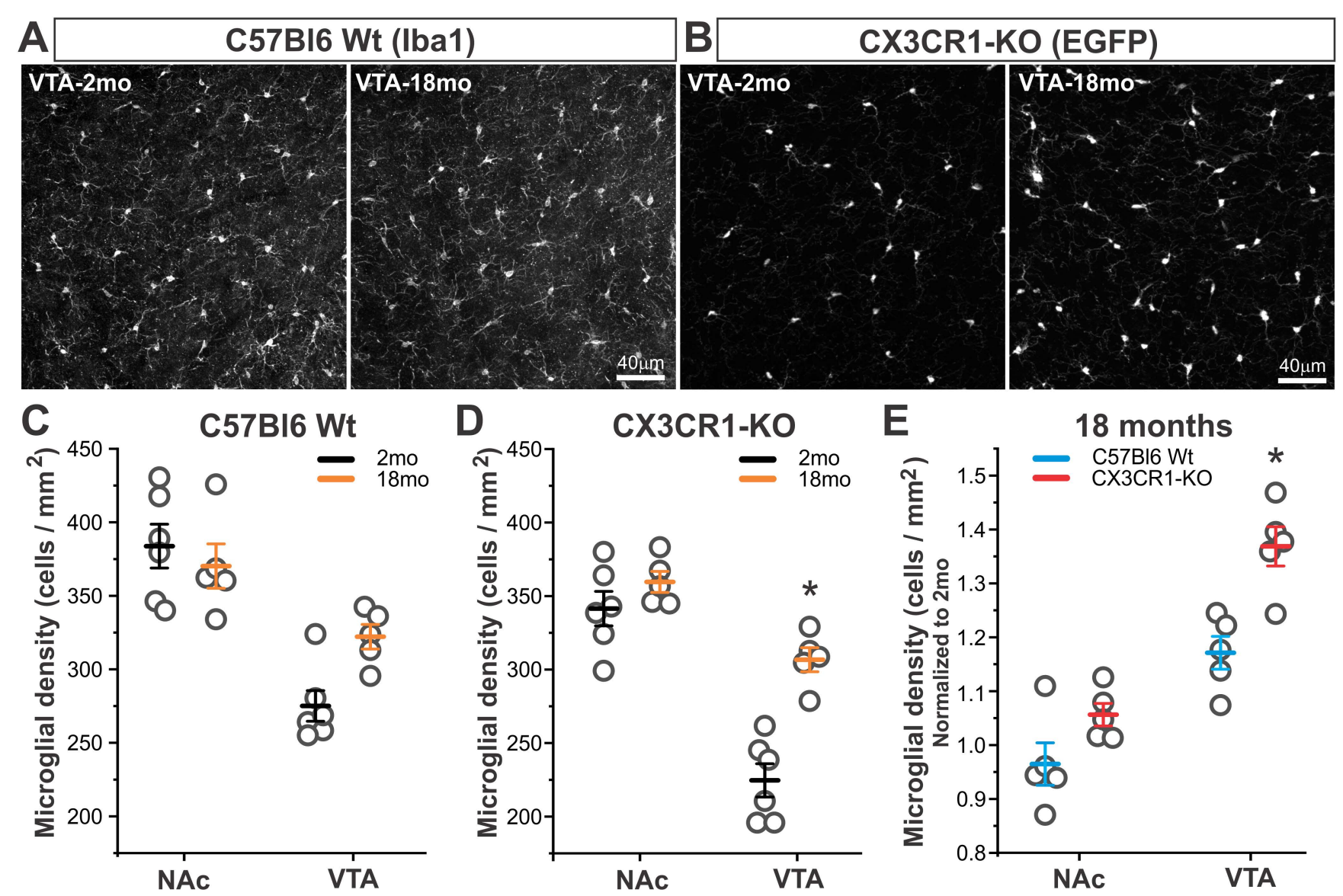

E
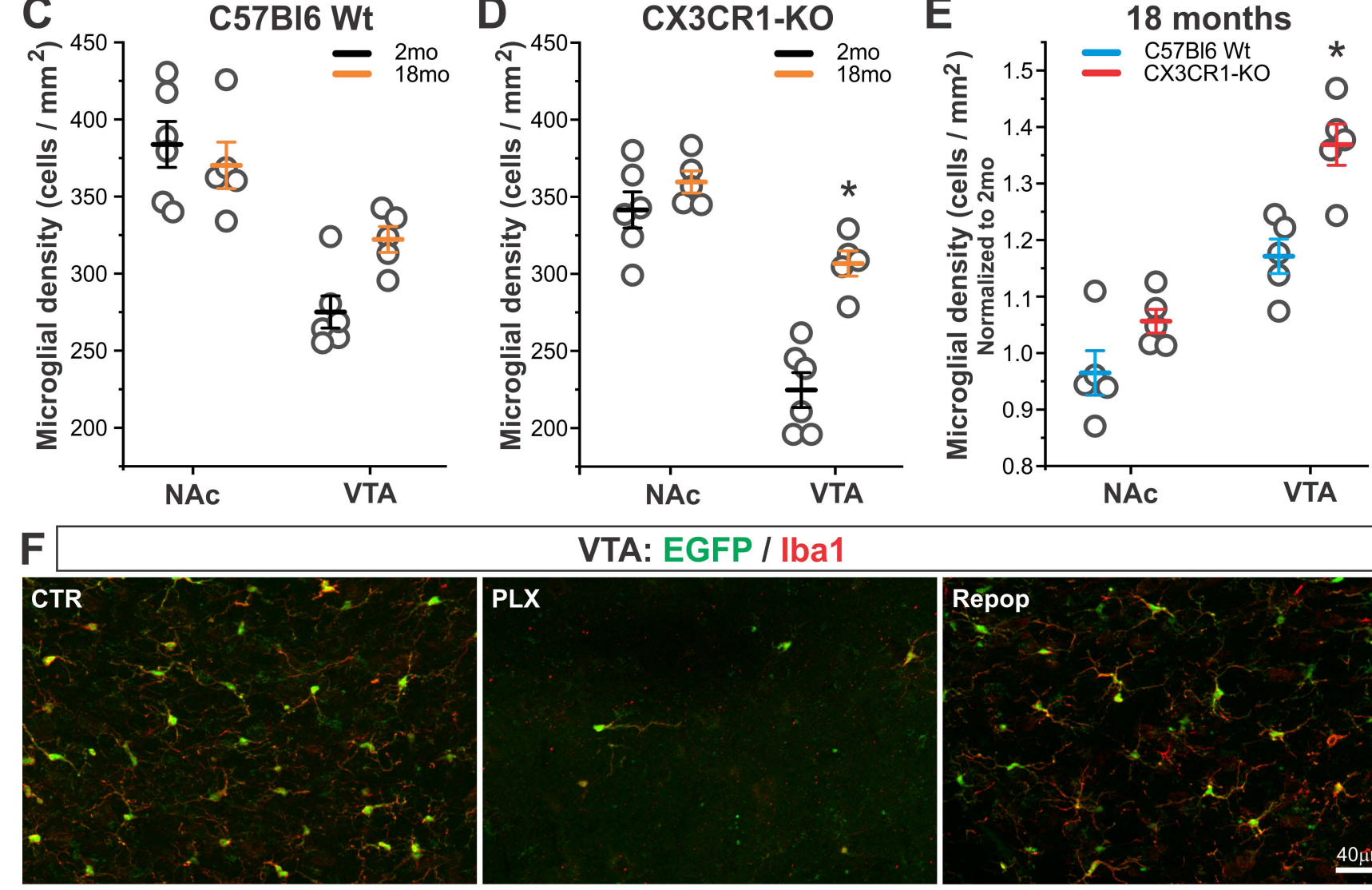

VTA: EGFP / lba1
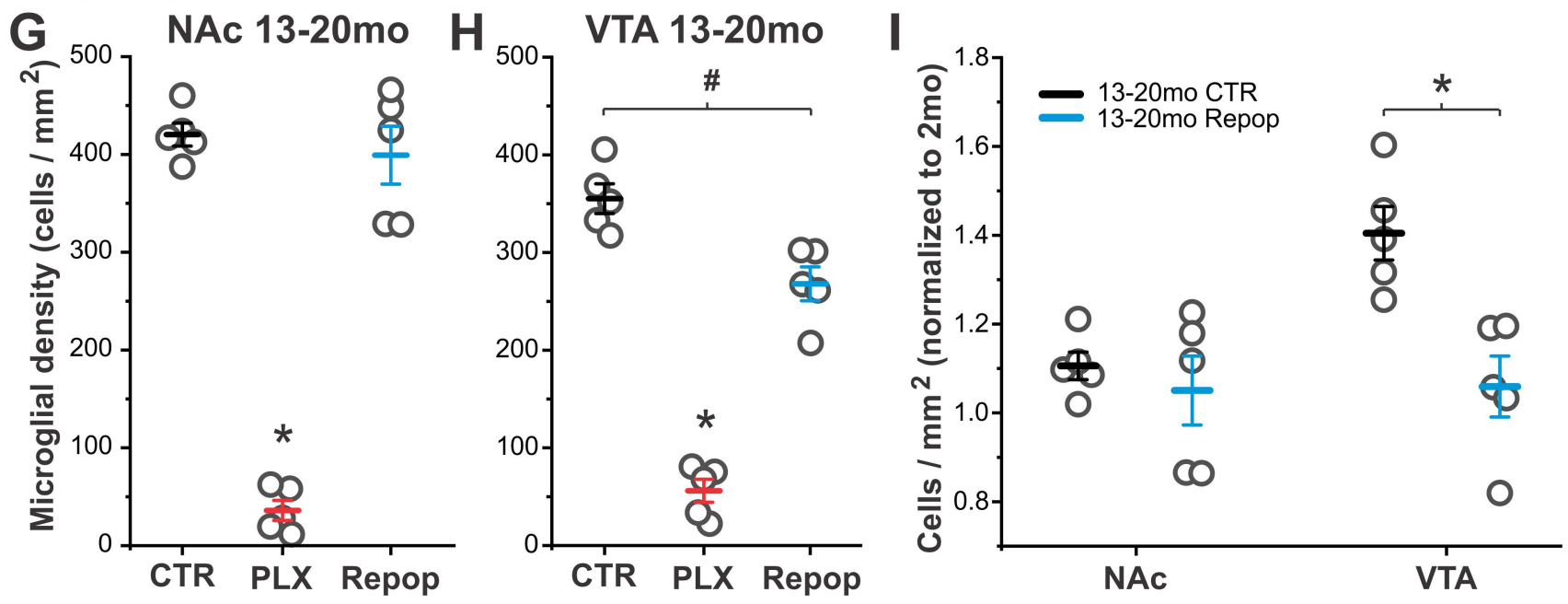